\title{
An alkaline follicular fluid fraction induces capacitation and limited release of oviduct epithelium-bound stallion sperm
}

\author{
Bart Leemans ${ }^{1}$, Bart M Gadella ${ }^{2,3}$, Tom A E Stout ${ }^{2,4}$, Hilde Nelis ${ }^{1}$, Maarten Hoogewijs ${ }^{1}$ and \\ Ann Van Soom ${ }^{1}$ \\ ${ }^{1}$ Department of Reproduction, Obstetrics and Herd Health, Faculty of Veterinary Medicine, Ghent University, \\ Salisburylaan 133, 9820 Merelbeke, Belgium, ${ }^{2}$ Departments of Farm Animal Health, ${ }^{3}$ Biochemistry and Cell Biology \\ and ${ }^{4}$ Equine Sciences, Faculty of Veterinary Medicine, Utrecht University, Utrecht, The Netherlands
}

Correspondence should be addressed to B Leemans; Email: baleeman.leemans@ugent.be

\begin{abstract}
Induction of hyperactivated motility is considered essential for triggering the release of oviduct-bound mammalian spermatozoa in preparation for fertilization. In this study, oviduct-bound stallion spermatozoa were exposed for $\mathbf{2}$ h to: i) pre-ovulatory and ii) post-ovulatory oviductal fluid; iii) $\mathbf{1 0 0} \%$ and iv) $\mathbf{1 0} \%$ follicular fluid (FF); v) cumulus cells, vi) mature equine oocytes, vii) capacitating and viii) non-capacitating medium. None of these triggered sperm release or hyperactivated motility. Interestingly, native FF was detrimental to sperm viability, an effect that was negated by heat inactivation, charcoal treatment and $30 \mathrm{kDa}$ filtration alone or in combination. Moreover, sperm suspensions exposed to treated FF at pH 7.9 but not $\mathrm{pH}^{7.4}$ showed $\mathrm{Ca}^{2+}$-dependent hypermotility. Fluo-4 AM staining of sperm showed elevated cytoplasmic $\mathrm{Ca}^{2+}$ in hyperactivated stallion spermatozoa exposed to treated $\mathrm{FF}$ at $\mathrm{pH} 7.9$ compared to a modest response in defined capacitating conditions at $\mathrm{pH} 7.9$ and no response in treated $\mathrm{FF}$ at $\mathrm{pH}$ 7.4. Moreover, $1 \mathrm{~h}$ incubation in alkaline, treated FF induced protein tyrosine phosphorylation in $20 \%$ of spermatozoa. None of the conditions tested induced widespread release of sperm pre-bound to oviduct epithelium. However, the hyperactivating conditions did induce release of 70-120 spermatozoa per oviduct explant, of which $48 \%$ showed protein tyrosine phosphorylation and all were acrosome-intact, but capable of acrosomal exocytosis in response to calcium ionophore. We conclude that, in the presence of elevated $\mathrm{pH}$ and extracellular $\mathrm{Ca}^{2+}$, a heat-resistant, hydrophilic, $<30 \mathrm{kDa}$ component of FF can trigger protein tyrosine phosphorylation, elevated cytoplasmic $\mathrm{Ca}^{2+}$ and hyperactivated motility in stallion sperm, but infrequent release of sperm pre-bound to oviduct epithelium.
\end{abstract}

Reproduction (2015) 150 193-208

\section{Introduction}

A 'sperm reservoir' is established in the oviductal isthmus of female mammals after mating and in anticipation of ovulation, and involves sperm binding via their head to oviduct epithelial cells, primarily at the level of the luminal cilia but also possibly via microvilli (Flechon \& Hunter 1981, Hunter 1987, 1991). Species-specific carbohydrate moieties expressed on the epithelium have been shown to underlie the binding with the sperm head (Suarez \& Pacey 2006), while the specific nature of the cell-cell contact triggers maturation of competent spermatozoa in a series of events collectively known as capacitation (Chang 1951, Austin 1952). Recently, we and others (Gonzalez-Fernandez et al. 2012, Aalberts et al. 2013, Leemans et al. 2014) have reported that an alkaline micro-environment within the equine oviduct leads to a gradual increase in sperm cytoplasmic $\mathrm{pH}$ which, in turn, correlates with increased phosphorylation of protein tyrosine residues. In vivo, it is hypothesized, these events are strictly coordinated to occur just before ovulation, when the pre-ovulatory follicle is preparing to release a mature oocyte (Hunter 1987, 1995).

Kirichok \& Lishko (2011) reported that both the low intracellular $\mathrm{Ca}^{2+}$ concentration and the high intracellular $\mathrm{H}^{+}$concentration, which prevail inside mouse and human spermatozoa, have a complementary, positive effect on sperm survival. It was hypothesized that these events occur during the oviductal binding phase. In the peri-ovulatory period, changes in the oviductal microenvironment provoke the final step in the capacitation process, predominantly by triggering $\mathrm{Ca}^{2+}$ influx into oviduct-bound spermatozoa. As a result of $\mathrm{Ca}^{2+}$ influx, a small subpopulation of spermatozoa resumes motility, which rapidly progresses to 
hyperactivated motility (Hunter et al. 1999) and generates sufficient force to detach the sperm from the oviduct epithelium such that they can escape from the mucosal pockets (Demott \& Suarez 1992, Lishko \& Kirichok 2010, Chang \& Suarez 2011). Supported by this newly generated power, the released and hyperactivated sperm are able to progress through the viscous fluid of the oviduct and up to the site of fertilization at the ampullary-isthmic junction (Suarez \& Pacey 2006, Suarez 2008a, Lishko \& Kirichok 2010, Chang \& Suarez 2011). Hyperactivation also assists the spermatozoa in penetrating the cumulus matrix and is essential for penetration of the zona pellucida to allow the fertilization of the oocyte (Publicover et al. 2007, Lishko et al. 2011).

At present, it is not entirely clear which biological factors trigger stallion sperm hyperactivation. Possible contributors, however, are likely to be present in oviduct epithelial secretions or around the cumulus-oocyte-complex (Suarez \& Pacey 2006, Suarez 2008a, Lishko \& Kirichok 2010, Chang \& Suarez 2011). The molecular basis of hyperactivation is also incompletely understood. Reports in mice suggest that opening of $\mathrm{H}^{+}$and $\mathrm{Ca}^{2+}$ ion channels present in the sperm plasma membrane is sufficient to allow $\mathrm{H}^{+}$efflux from and $\mathrm{Ca}^{2+}$ influx to the sperm cytosol, along their respective concentration gradients (Kirichok \& Lishko 2011). The primary source of $\mathrm{Ca}^{2+}$ for the spermatozoon is thus extracellular. An intracellular $\mathrm{Ca}^{2+}$ store is also available in the lumen of the redundant nuclear envelope (RNE) located at the base of the flagellum (Chang \& Suarez 2011) but, while this internal $\mathrm{Ca}^{2+}$ store could provide sufficient $\mathrm{Ca}^{2+}$ for the induction of hyperactivation, external $\mathrm{Ca}^{2+}$ influx is required to maintain intracellular $\mathrm{Ca}^{2+}$ at a level sufficient to sustain hyperactivation (Marquez et al. 2007). The $\mathrm{Ca}^{2+}$ influx can be realized by the activation of specific CatSper channels, located at the principal piece of the tail (Quill et al. 2001, Ren et al. 2001, Suarez 2008b, Chang \& Suarez 2011). Only spermatozoa with increased intracellular $\mathrm{pH}$ (due to $\mathrm{H}^{+}$efflux) are able to activate their CatSper channels, and the resulting $\mathrm{Ca}^{2+}$ influx induces the high-amplitude, asymmetrical flagellar beating of the axoneme that is characteristic of hyperactivated motility (Ho et al. 2002, Kirichok et al. 2006, Suarez 2008b).

In contrast to mouse sperm, the trigger that activates $\mathrm{Ca}^{2+}$ influx into stallion spermatozoa has yet to be identified. On the other hand, the oviduct is the site where spermatozoa should acquire hyperactivated motility physiologically (Hunter et al. 1999). It has been hypothesized that non-capacitated spermatozoa must first bind to the oviduct epithelium before they are able to be hyperactivated and released (Yanagimachi 1994). If release of hyperactivated sperm is specific to the late follicular development stage, oviductal secretions or sperm contact with oviduct cells exposed to specific endocrine stimuli might be involved in the acquisition of hyperactivity, whereas hyperactivation induced after ovulation could be driven by factors originating from the ovulating follicle (oocyte-cumulus mass and follicular fluid (FF)). Differences in the mechanism for triggering sperm hyperactivation exist between species (human: Yao et al. 2000; rabbit: Harper 1973a; mouse: Suarez \& Osman 1987; cattle: Marquez \& Suarez 2007). The current study aims to elucidate the conditions that trigger hyperactivated motility of stallion spermatozoa in the mare's oviduct and determine whether the release of capacitated sperm from oviduct epithelial cells could be achieved under in vitro conditions.

\section{Materials and methods}

\section{Chemicals and reagents}

Dulbecco's phosphate-buffered saline (DPBS), fetal bovine serum (FBS) (Batch: 07G8814F) and DMEM/Nutrient Mixture F-12 (DMEM-F12) were purchased from Gibco Life Technologies. Propidium iodide (PI), SYBR14 (LIVE/DEAD Sperm Viability kit), Hoechst 33342, Alexa Fluor 488-conjugated goat anti-mouse antibody and fluo-4 AM were obtained from Molecular Probes (Ghent, Belgium). Monoclonal 4G10 Platinum, anti-phosphotyrosine mouse antibody was obtained from Millipore (Overijse, Belgium). Triton X-100, PNA-FITC, fatty acid-free BSA (A9418; cell culture tested), EDTA, procaine hydrochloride, calcium ionophore A23187 and all other chemicals not listed otherwise were obtained from Sigma-Aldrich.

\section{Animals}

Oviducts were collected at a slaughterhouse (Euro Meat Group, Moeskroen, Belgium) soon after the slaughter of healthy warmblood mares aged between 5 and 22 years and without any visible reproductive tract pathologies (Leemans et al. 2014). Only oviducts from mares with a large follicle (>35 mm diameter) in combination with estrous oedema in the uterine wall, indicating imminent ovulation, were used to prepare oviduct explants.

\section{Preparation of oviduct explants}

Five oviducts per experiment were prepared as previously described by Nelis et al. (2014). Briefly, epithelial cells were harvested from oviducts of preovulatory mares by scraping the mucosa at the ampullary-isthmic junction of the longitudinally incised oviduct. The harvested cellular material was washed and re-suspended twice in $3 \mathrm{ml}$ fresh HEPES-buffered TALP washing medium (Rathi et al. 1999). Next, the cells were cultured overnight in DMEM/F12 with $10 \%$ FBS at $38.5{ }^{\circ} \mathrm{C}$ in a humidified atmosphere of $5 \% \mathrm{CO}_{2}$ in air. The time from the slaughter of mares to cell culture was $\sim 3-4 \mathrm{~h}$.

\section{Semen collection and preparation}

Semen was collected from three stallions of proven fertility using a Colorado model artificial vagina (Animal Reproduction Systems, Chino, CA, USA). The raw ejaculate was filtered through gauze to remove the gel fraction and any debris. 
Samples with good motility ( $>70 \%$ motile sperm) were transported immediately to the laboratory for further processing. One millilitre of fresh semen was then centrifuged over a 45/90\% Percoll gradient (Parrish et al. 1988, Tremoleda et al. 2003). Next, the sperm pellet was washed once with Whitten's medium ('non-capacitating medium': $100 \mathrm{mM} \mathrm{NaCl}, 4.7 \mathrm{mM}$ $\mathrm{KCl}, 1.2 \mathrm{mM} \mathrm{MgCl}_{2}, 5.5 \mathrm{mM}$ glucose, $22 \mathrm{mM}$ HEPES, $2.4 \mathrm{mM}$ sodium lactate and $1.0 \mathrm{mM}$ pyruvic acid; $\mathrm{pH}=7.4$ and 280$300 \mathrm{mOsm} / \mathrm{kg}$; (McPartlin et al. 2008) and subsequently diluted to a concentration of $20 \times 10^{6}$ spermatozoa $/ \mathrm{ml}$ in noncapacitating medium. Each experiment was performed using one ejaculate from each of the three stallions. The study was approved by the Ethics Committee of the Faculty of Veterinary Medicine of Ghent University (EC2013/175 and EC2013/176).

\section{Sperm-oviduct explant binding and induction of capacitation}

We previously described the establishment of sperm-oviduct explants in which bound spermatozoa can be induced to exhibit protein tyrosine phosphorylation in their tail (Leemans et al. 2014). In brief, oviduct explants were cultured in a DMEM/F12based medium, and equilibrated with $5 \% \mathrm{CO}_{2}$ in a humidified atmosphere at $38.5^{\circ} \mathrm{C}$, as described by Nelis et al. (2014). Sperm binding to oviduct explants ( 5 per $45 \mu$ l droplet) was performed in the non-capacitating medium at $38.5{ }^{\circ} \mathrm{C}$ in air. The capacitating medium was made by substituting the sodium lactate in the non-capacitating medium with $2.4 \mathrm{mM} \mathrm{CaCl}_{2}$ and adding $25 \mathrm{mM} \mathrm{NaHCO}_{3}$ and $7 \mathrm{mg} / \mathrm{ml} \mathrm{BSA}$ ( $\mathrm{pH}=7.4$ and 280$300 \mathrm{mOsm} / \mathrm{kg}$; osmolality was adjusted by adding the $\mathrm{NaCl}$ in steps) (adapted from McPartlin et al. (2008)). In general, a final concentration of $2 \times 10^{6}$ spermatozoa/ml was used. After a $2-\mathrm{h}$ co-incubation in the non-capacitating medium, sperm-oviduct explants were washed twice and transferred to the capacitating/ hyperactivating medium for $2 \mathrm{~h}$. Each replicate was performed with one ejaculate from a different stallion.

\section{Collection of fluids and cells that sperm may contact in the sperm reservoir}

For each experiment, pre- and post-ovulatory stage oviducts and ovaries containing a pre-ovulatory follicle (diameter $>35 \mathrm{~mm}$ ) were collected at the slaughterhouse and immediately transported to the laboratory. Oviducts were trimmed and flushed successively with $1 \mathrm{ml}$ of the capacitating medium. Next, the oviduct flushing fluid was filtered through a $0.2 \mu \mathrm{m}$ Acrodisc Syringe Filter with a Supor Membrane (Pall Corporation Life Sciences, Ghent, Belgium).

$\mathrm{FF}(\mathrm{pH} \approx 7.2)$ was collected from five pre-ovulatory follicles (diameter $>35 \mathrm{~mm}$ ). Cumulus-oocyte complexes were recovered from the aspirated FF and matured by incubation in FF for $28 \mathrm{~h}$ at $38.5{ }^{\circ} \mathrm{C}$ in $5 \% \mathrm{CO}_{2}$ in air. Subsequently, oocytes were denuded of their cumulus investment by gentle mouth pipetting. The remaining FF was centrifuged at $100 \mathrm{~g}$ for $10 \mathrm{~min}$ at $22^{\circ} \mathrm{C}$ before the supernatant was filtered as described for oviduct flushing fluids. Both cell suspensions and collected fluids were incubated for $2 \mathrm{~h}$ with sperm bound to oviduct explants to evaluate their effects on sperm hyperactivation and sperm release.

\section{Treatment of FF}

Freshly filtered ( $2 \mu \mathrm{m}$ diameter) $\mathrm{FF}(\mathrm{pH} \approx 7.2)$ was treated in five different ways: i) centrifuged through a $100 \mathrm{kDa}$ filter (10 min at $14000 \mathrm{~g}$; Amicon Ultra- $0.5 \mathrm{ml}$ Centrifugal Filters for Protein Purification and Concentration: Millipore) to see whether the effects of whole FF were elicited by molecules < $100 \mathrm{kDa}$; ii) by heat inactivation in a $55{ }^{\circ} \mathrm{C}$ water bath for $0.5 \mathrm{~h}$ (Triglia \& Linscott 1980, Giard 1987, Pinyopummintr \& Bavister 1994) to examine whether the FF factor was heat-resistant; iii) charcoal treatment as described by Cheng et al. (1998) to examine whether a lipid or lipid-bound factor, including steroid hormones (Quirk \& Fortune 1986), was implicated. For charcoal treatment, pooled FF was stirred at ambient temperature for $45 \mathrm{~min}$ with $50 \mathrm{mg}$ charcoal $/ \mathrm{ml}$ (Norit: activated and neutralized; Sigma) and then centrifuged at $4500 \mathrm{~g}$ for $1 \mathrm{~h}$ at $4{ }^{\circ} \mathrm{C}$. The supernatant was filtered through a $0.2 \mu \mathrm{m}$ Acrodisc Syringe Filter with a Supor Membrane (Pall Corporation Life Sciences), to remove any remaining charcoal particles; iv) centrifuged through a $30 \mathrm{kDa}$ filter (30 min$3000 \mathrm{~g}$; Vivaspin 15R, Sartorius Biolab Products, Goettingen, Germany) to examine whether the FF factor MW was $<30 \mathrm{kDa}$; v) triple-treated to see if the effects were still apparent after successive heat-inactivation, charcoal treatment and $30 \mathrm{kDa}$ filtration; and vi) some heat-inactivated, charcoaltreated, $30 \mathrm{kDa}$-filtered or triple-treated FF samples were incubated in air until the $\mathrm{pH}$ rose to 7.9. Similar treatments were performed with the capacitating medium. All treated FF samples were stored in aliquots at $-80{ }^{\circ} \mathrm{C}$ until further use. To prevent $\mathrm{pH}$ changes in elevated $\mathrm{pH}$ treated FF and capacitating medium during sperm incubation, experiments were performed in closed $1 \mathrm{ml}$ tubes (Greiner Bio-One, Vilvoorde, Belgium) to prevent contact with air.

\section{Sperm viability assay}

To examine the membrane integrity of spermatozoa attached to or released from the oviduct explants, spermatozoa and spermoviduct explants were respectively washed by centrifugation $\left(600 \mathrm{~g}\right.$ for $5 \mathrm{~min}$ ) or transferred to pre-warmed DPBS $\left(37^{\circ} \mathrm{C}\right)$ and stained with the nucleic acid stains SYBR14 $(20 \mu \mathrm{M})$ and PI (50 nM) (LIVE/DEAD Sperm Viability kit; Molecular Probes, Leiden, The Netherlands) (De Pauw et al. 2002). Stained spermatozoa and sperm-oviduct explants were washed and mounted on pre-warmed glass slides (Marienfeld, Lauda-Königshofen, Germany). Sperm with green fluorescence-labelled nuclei were considered viable, whereas sperm with red-stained nuclei were considered dead. Finally, the percentages of viable spermatozoa were scored by counting 200 randomly selected released spermatozoa. Samples were examined using a Leica DMR microscope equipped with a mercury lamp and appropriate filters at a magnification of $400 \times$.

\section{Quantification of tail-associated protein tyrosine phosphorylation}

Incubated sperm preparations were washed twice and fixed in $4 \%$ paraformaldehyde in DPBS at room temperature for $15 \mathrm{~min}$ as described previously (Leemans et al. 2014). Fixed 
spermatozoa were washed and incubated in $0.1 \%$ Triton X-100 in DPBS for $10 \mathrm{~min}$ at room temperature. The permeabilised spermatozoa were then incubated in blocking buffer (DPBS containing $1 \% \mathrm{BSA}$ ) for $10 \mathrm{~min}$ at room temperature. Next, spermatozoa were incubated overnight at $4{ }^{\circ} \mathrm{C}$ in buffer containing $0.1 \%$ BSA and the mouse monoclonal $4 \mathrm{G} 10$ Platinum $\operatorname{IgG}_{2 \mathrm{~b}}$ protein anti-phosphotyrosine antibody (diluted 1:500). After incubation, spermatozoa were washed and stained with a monoclonal goat anti-mouse antibody conjugated to Alexa Fluor 488 (Invitrogen, Molecular Probes, Ghent, Belgium) for $1 \mathrm{~h}$ at room temperature. The immunelabelled spermatozoa were mounted on glass slides under a cover slip. The proportion of spermatozoa with green fluorescent tails among the total sperm population (with Hoechst 33342 fluorescent heads) was determined by randomly scoring 200 spermatozoa. Samples were examined using a Leica DMR microscope equipped with a mercury lamp and appropriate filters at a magnification of $400 \times$.

\section{Sperm acrosome status}

The acrosome status of spermatozoa was assessed using fluorescein-conjugated peanut agglutinin (PNA-FITC) to discriminate acrosome-intact spermatozoa from acrosomedeteriorated or -reacted spermatozoa (Rathi et al. 2001). In brief, after fixation in 4\% (w/v) paraformaldehyde in DPBS for $15 \mathrm{~min}$ at room temperature, spermatozoa were washed in DPBS and permeabilised in $0.1 \%$ Triton X-100 in DPBS for $10 \mathrm{~min}$ at room temperature (Leemans et al. 2014). After washing, spermatozoa were stained for $15 \mathrm{~min}$ at room temperature with $1 \mu \mathrm{g} / \mathrm{ml}$ PNA-FITC and subsequently washed and mounted as described above. Spermatozoa with PNAFITC-labelled acrosome regions were considered acrosomeintact, whereas spermatozoa with no fluorescence over the acrosomal region were considered acrosome-reacted or deteriorated. The percentages of acrosome-intact spermatozoa were scored by examining 200 spermatozoa using a Leica DMR microscope equipped with a mercury lamp and appropriate filters at a magnification of $400 \times$.

\section{Cytoplasmic $\mathrm{Ca}^{2+}$ imaging in stallion spermatozoa}

Stallion spermatozoa were washed in non-capacitating medium and stained for $30 \mathrm{~min}$ in $5 \mu \mathrm{M}$ of the $\mathrm{Ca}^{2+}$-sensitive dye fluo-4 AM in non-capacitating medium at $38.5^{\circ} \mathrm{C}$. Spermatozoa were washed and incubated for an additional $20 \mathrm{~min}$ at $38.5^{\circ} \mathrm{C}$ to allow de-esterification of the fluo-4 AM probe before analysis. Subsequently, fluo-4 AM-loaded sperm suspensions $\left(10 \times 10^{6}\right.$ spermatozoa $\left./ \mathrm{ml}\right)$ were incubated for $0.5 \mathrm{~h}$ in different capacitating or hyperactivating media. Next, the sperm suspensions were mounted on glass slides as described previously. The intensity of the Fluo-4 AM signal correlates with the cytoplasmic $\mathrm{Ca}^{2+}$ concentration. In this study, we used the cytoplasmic $\mathrm{Ca}^{2+}$ signal from sperm incubated in capacitating medium at $\mathrm{pH} 7.4$ as the reference intensity. Increased cytoplasmic $\mathrm{Ca}^{2+}$ signal during incubation was taken to indicate external $\mathrm{Ca}^{2+}$-dependent capacitation or hypermotility. The percentages of spermatozoa with increased cytoplasmic $\mathrm{Ca}^{2+}$ was scored by examining 200 spermatozoa and using a Leica DMR microscope equipped with a mercury lamp and appropriate filters at a magnification of $1000 \times$.

\section{Sperm motility assessment}

Sperm motility patterns were assessed using a CCD ICD-46E camera (Ikegami Tsushinki Co. Ltd, Japan) attached to an Olympus IX70 inverted microscope (Olympus Belgium N.V.). Images were acquired using the Image Database program (Leica, Van Hopplynus N.V., Brussel, Belgium).

Motility parameters of spermatozoa in suspension were evaluated using a computer-assisted sperm analyzer (CASA: Hamilton-Thorne Ceros 12.3). Under defined capacitating conditions, BSA was replaced with polyvinyl alcohol (PVA) to avoid the sperm agglutination observed after centrifugation in BSA-containing medium (Loux et al. 2013). For each analysis, $10 \mu \mathrm{l}$ of sperm suspension diluted in the various treated FF or capacitating media was mounted on a pre-warmed glass slide (Marienfeld) and maintained at $37^{\circ} \mathrm{C}$ using a Tokai Hit thermo plate. Five randomly selected microscopic fields in the center of the slide were scanned four times each, generating 20 scans for every sample. The mean of the five scans for each microscopic field was used for statistical analysis. The settings of the CASA-Software HTR 12.3 for analysing motility parameters of stallion sperm were based on Loomis \& Graham (2008) and described previously by Hoogewijs et al. (2010). To evaluate hyperactivated motility, six different parameters were initially evaluated: total motile sperm (TM; \%), progressively motile sperm (PM; \%), amplitude of lateral head displacement $(\mathrm{ALH} ; \mu \mathrm{m})$, curvilinear velocity $(\mathrm{VCL} ; \mu \mathrm{m} / \mathrm{s})$, straightness (STR) and linearity (LIN). These parameters help detect increased vigour and asymmetry of flagellar movement during hyperactivation and have been associated with hyperactivated motility in bovine (Marquez \& Suarez 2007) and equine (Rathi et al. 2001) sperm. Ultimately, the ALH and the VCL proved to be most useful for classifying hyperactivated motility in stallion sperm (McPartlin et al. 2009, Loux et al. 2013).

\section{Sperm and oviduct explant co-incubation}

Groups of five sperm-oviduct explants established in noncapacitating medium, were incubated for $2 \mathrm{~h}$ in $50 \mu \mathrm{l}$ droplets under oil containing i) fluid flushed from the oviducts of mares slaughtered pre-ovulation; ii) fluid flushed from post-ovulation mare oviducts; iii) $100 \%$ FF; iv) $10 \%$ FF diluted in capacitating medium; v) capacitating medium containing equine cumulus cells; vi) capacitating medium containing mature (MII) equine oocytes; vii) capacitating medium and viii) non-capacitating medium; all conditions were tested at both $\mathrm{pH} 7.4$ and $\mathrm{pH} 7.9$ except the non-capacitating medium $\mathrm{pH}$ 7.9. Counting of the number of spermatozoa bound per $\mathrm{mm}^{2}$ sperm-oviduct explant was blinded to treatment groups.

Subsequently, sperm incubated in pure fresh FF $(0,10$ or $100 \%)$ at $\mathrm{pH} 7.4$ and 7.9 were scored for plasma membrane and acrosome integrity and for CASA motility parameters. Additionally, the effect of fresh FF on oviduct explant viability was evaluated by examining ciliary activity and cell membrane integrity.

Next, viability parameters of suspended sperm incubated in i) $100 \mathrm{kDa}$-filtered fresh $\mathrm{FF}$, ii) heat-inactivated FF, 
iii) charcoal-treated FF, iv) $30 \mathrm{kDa}$-filtered fresh FF and v) triple-treated (heat-inactivated, charcoal-treated and $30 \mathrm{kDa}$-filtered) FF were examined during a $6 \mathrm{~h}$ incubation.

Subsequently, the various motility parameters indicating hyperactivated motility of suspended sperm $\left(10 \times 10^{6}\right.$ spermatozoa $/ \mathrm{ml}$ ) incubated in 100\% heat-inactivated FF, 100\% charcoal-treated FF, 30 kDa-filtered FF and 100\% triple-treated FF at both $\mathrm{pH} 7.4$ and $\mathrm{pH} 7.9$ were evaluated by CASA over time.

After $0.5 \mathrm{~h}$ of incubation in i) heat-inactivated $\mathrm{FF}$, ii) charcoal-treated FF, iii) 30 kDa-filtered FF, iv) triple-treated FF and v) capacitating medium, the lateral head displacement and $\mathrm{VCL}$ (indicating hyperactived motility) of spermatozoa in suspension $\left(10 \times 10^{6}\right.$ spermatozoa $\left./ \mathrm{ml}\right)$ were monitored. All FF conditions were tested at both $\mathrm{pH} 7.9$ and 7.4 in three concentrations: i) $100 \% \mathrm{FF}$, ii) $50 \% \mathrm{FF}$ and iii) $10 \% \mathrm{FF}$. In addition, the $\mathrm{Ca}^{2+}$ dependency of hyperactivated motility was assessed in all undiluted treated FF and capacitating medium at $\mathrm{pH} 7.9$ and 7.4 by adding 2 mM EDTA.

Next, the portion of spermatozoa that showed cytoplasmic $\mathrm{Ca}^{2+}$ influx was assessed by fluo-4 AM in sperm $\left(10 \times 10^{6}\right.$ spermatozoa $/ \mathrm{ml}$ ) incubated for $0.5 \mathrm{~h}$ in i) capacitating medium, ii) $100 \%$ heat-inactivated $\mathrm{FF}$, iii) $100 \%$ charcoal-treated, iv) $100 \% 30 \mathrm{kDa}$-filtered FF and v) $100 \%$ triple-treated FF at both $\mathrm{pH} 7.4$ and $\mathrm{pH} 7.9$.

After $1 \mathrm{~h}$ incubation, membrane integrity, protein tyrosine phosphorylation and acrosome status were assessed in nine different conditions at elevated $\mathrm{pH} 7.9$ : i) $100 \%$ and ii) $10 \%$ heat-inactivated FF, iii) $100 \%$ and iv) $10 \%$ charcoal-treated FF, v) $100 \%$ and vi) $10 \% 30 \mathrm{kDa}$-filtered $\mathrm{FF}$, vii) $100 \%$ and viii) $10 \%$ triple-treated FF and ix) capacitating medium. Subsequently, the functionality of the sperm to undergo the acrosome reaction was scored after incubation in identical FF conditions ( $\mathrm{pH}$ 7.9) followed by exposure to $5 \mu \mathrm{M}$ calcium ionophore A23187 for 30 min.

In addition, sperm-oviduct explants incubated in capacitating media for $2 \mathrm{~h}$ were washed twice and transferred to i) $100 \%$ and ii) $10 \%$ heat-inactivated $\mathrm{FF}$; iii) $100 \%$ and iv) $10 \%$ charcoal-treated FF; v) $100 \%$ and vi) $10 \% 30 \mathrm{kDa}$-filtered FF, vii) $100 \%$ and viii) $10 \%$ triple-treated $F F$, ix) $5 \mathrm{mM}$ procaine hydrochloride in capacitating medium and $\mathrm{x}$ ) capacitating medium, to determine whether induction of hyperactivation in spermatozoa bound to oviduct explants induced sperm release. Two pHs (7.4 and 7.9) were tested for each condition. The number of released spermatozoa per oviduct explant and the change in the number of spermatozoa bound per $\mathrm{mm}^{2}$ spermoviduct explant were counted, blind to the treatment.

Ultimately, released spermatozoa in all the hyperactivating conditions (100\% heat-inactivated FF pH 7.9, 100\% charcoaltreated FF pH 7.9, 100\% $30 \mathrm{kDa}$-filtered FF pH 7.9, 100\% triple-treated $\mathrm{FF} \mathrm{pH} 7.9,5 \mathrm{mM}$ procaine in capacitating medium $\mathrm{pH} 7.4$ and $5 \mathrm{mM}$ procaine in capacitating medium $\mathrm{pH}$ 7.9) were assessed after $2 \mathrm{~h}$ for membrane and acrosome integrity and tail-associated protein tyrosine phosphorylation.

\section{Statistical analysis}

The effects of treatments on sperm parameters were assessed by ANOVA. Significant differences in the number of spermatozoa released from oviduct binding, displaying motility parameters indicating hyperactivated motility (TM, PM, ALH, VCL, STR and LIN) and the percentages of viable spermatozoa were determined using repeated measures ANOVA with Greenhouse-Geisser and Bonferroni corrections, as implemented in the general linear model. The same statistical test was used to assess changes in the percentage of tail-associated protein tyrosine phosphorylated ( $\mathrm{PY}+$ ), acrosome-reacted spermatozoa or spermatozoa with an increased cytoplasmic $\mathrm{Ca}^{2+}$ concentration over time. Scheffé post-hoc tests were performed for pairwise comparisons. Statistical analysis and graph plotting were performed using SPSS version 20 for Windows (SPSS IBM). Differences were considered significant if $P<0.05$.

\section{Results}

Oviduct epithelium-bound sperm cells are not released by exposure to fluids and cells that they may encounter during sperm-oviduct binding at either $\mathrm{pH} 7.4$ or $\mathrm{pH} 7.9$

At the time of ovulation in vivo, the equine oviduct is thought to have an alkaline micro-environment (Leemans, et al. 2014). At this time, a population of oviduct-bound sperm is released from the sperm reservoir to proceed to the ampulla of the mare's oviduct and accomplish fertilization, after induction of hyperactivated motility. In the first experiment, oviduct explants with bound stallion spermatozoa $(\sim 120000$ spermatozoa bound per $\mathrm{mm}^{2}$; Fig. 1) were incubated at

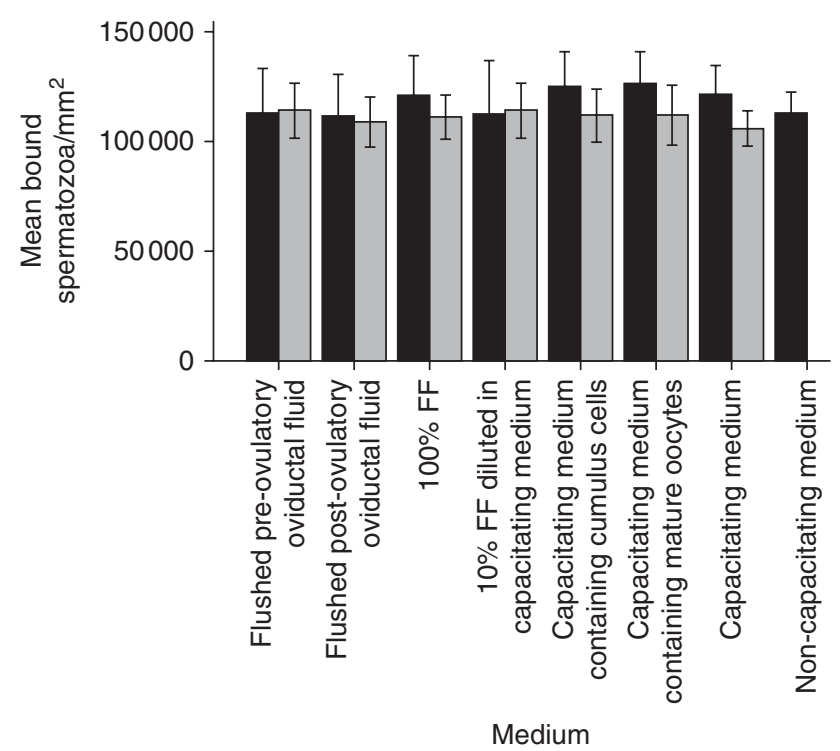

Figure 1 Mean ( \pm S.D.) number of stallion spermatozoa bound per $\mathrm{mm}^{2}$ equine oviduct epithelium, assessed after $2 \mathrm{~h}$ incubation at both $\mathrm{pH} 7.4$ (black bars) and 7.9 (grey bars) with i) oviductal flush fluid from mares slaughtered pre-ovulation; ii) oviductal flush fluid from mares slaughtered post-ovulation; iii) $100 \%$ fresh follicular fluid (FF); iv) $10 \%$ fresh FF in capacitating medium; v) equine cumulus cells in capacitating medium; vi) mature (MII) equine oocytes in capacitating medium; vii) capacitating medium; or viii) non-capacitating medium (control) $(P>0.05)$. Data represent four replicates ( $n=40$ per group) analysed by one-way ANOVA with post hoc Bonferroni tests for pairwise comparisons. 
both $\mathrm{pH} 7.4$ and 7.9 and exposed to the various fluids and cells that they should encounter in vivo. After $2 \mathrm{~h}$ of sperm-oviduct explant incubation at both $\mathrm{pH} 7.4$ and 7.9 , no significant sperm release was observed following exposure to either: i) fluid flushed from the oviducts of mares slaughtered pre-ovulation; ii) fluid flushed from post-ovulation mare oviducts; iii) 100\% FF iv); $10 \% \mathrm{FF}$ diluted in capacitating medium; v) capacitating medium containing equine cumulus cells, vi) capacitating medium containing mature (MII) equine oocytes, vii) capacitating medium and viii) non-capacitating medium $\mathrm{pH} 7.4$ ( $P>0.33$ for all comparisons; Fig. 1). The few spermatozoa released in each treatment were nearly all membrane-damaged and immotile (data not shown).

\section{Fresh FF has a detrimental effect on sperm membrane integrity and motility at both $\mathrm{pH} 7.4$ and 7.9}

Fresh FF had a detrimental effect on sperm at both $\mathrm{pH} 7.4$ and 7.9, regardless of whether the sperm were bound to oviduct explants or in suspension. The detrimental effects on sperm membrane and acrosome integrity were apparent in undiluted and in tenfold diluted FF, albeit that at the tenfold dilution the deteriorating effects of FF were ameliorated (see Fig. 2). In each of the three incubation conditions at $\mathrm{pH} 7.4$, a significant decrease in the percentage of sperm with intact membranes was observed over time, such that after $6 \mathrm{~h}$ in capacitating $(0 \%$ FF) conditions significantly more spermatozoa remained membrane-intact $(38 \pm 6 \%)$ than after incubation in $10 \%$ fresh FF $(15 \pm 3 \%)(P<0.001)$. When sperm suspensions were incubated in $100 \%$ fresh $\mathrm{FF}$, the deterioration was even more rapid $(P<0.001$ for all comparisons between the three different FF conditions except time point $0 \mathrm{~h}$ ). After $30 \mathrm{~min}$ incubation, only
$14 \pm 6 \%$ of the sperm population in $100 \%$ FF was still membrane-intact, and after $1 \mathrm{~h}<10 \%$ of the sperm were still viable. The percentage of motile sperm showed a similar deterioration to membrane integrity over time for the three incubation conditions. The destructive effect of FF on plasma membrane integrity and motility did not immediately cause deterioration of the acrosome (Fig. 2). Only after more than $1 \mathrm{~h}$ of incubation was acrosome deterioration observed in $10 \%(21 \pm 5 \%$ after $6 \mathrm{~h}$; $P=0.02)$ and $100 \%(48 \pm 8 \%$ after $3 \mathrm{~h} ; P<0.001) \mathrm{FF}$ conditions, although this was more marked than in capacitation medium where no significant induction of acrosome deterioration was seen $(8 \pm 4 \%$ after $6 \mathrm{~h}$; Fig. 2). Very similar changes were observed using the same conditions at $\mathrm{pH} 7.9$ (Fig. 2). Thus, regardless of $\mathrm{pH}$ (7.4. vs 7.9), fresh FF caused concentration-dependent sperm deterioration. In contrast, fresh FF did not detrimentally affect the viability of the oviduct epithelial cells lining the explants. The oviduct explants remained viable for at least $24 \mathrm{~h}$ when incubated in $10 \%$ or $100 \%$ fresh $\mathrm{FF}$ at $\mathrm{pH} 7.4$, and the epithelial cells displayed similar ciliary activity between media and over time $(100 \pm 0 \%)$; almost all cells $(>99 \%)$ of nearly all explants $(95 \pm 9 \% ; P=0.84)$ remained membrane-intact. Similar findings applied for incubation at pH 7.9 (Fig. 3).

\section{A 30-100 kDa heat-instable lipophilic FF factor is responsible for sperm deterioration}

Fresh FF was treated in five different ways to elucidate properties of the sperm-deteriorating substance(s): i) centrifugation though a $100 \mathrm{kDa}$ filter (to remove large proteins), ii) heat inactivation (to neutralize tertiary and quaternary folded proteins, including complement factors, by protein denaturation), iii) charcoal treatment

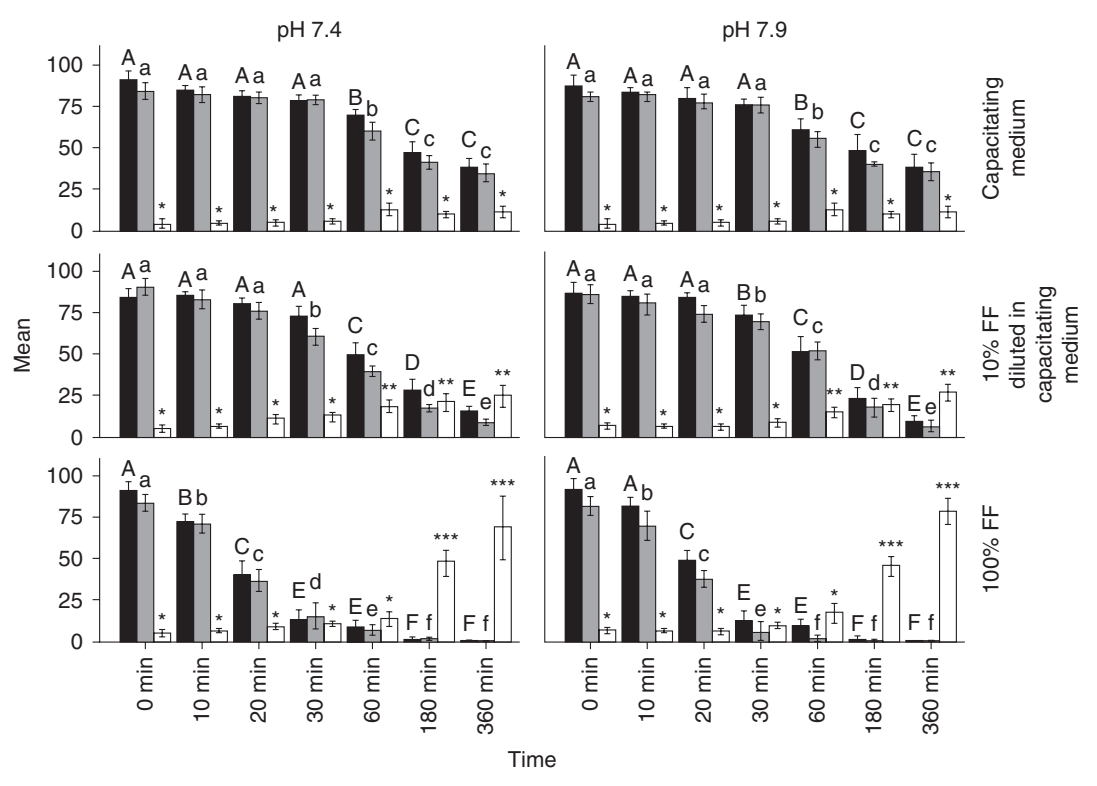

Figure 2 Stallion sperm viability during $6 \mathrm{~h}$ incubation at both $\mathrm{pH} 7.4$ and 7.9 in capacitating medium, $10 \%$ fresh follicular fluid (FF) diluted in capacitating medium and $100 \%$ fresh FF. The graphs depict mean ( \pm s.D.) percentages of membrane-intact (black bars), motile (dark grey) and acrosome-reacted spermatozoa (light grey) ( $n=200$ spermatozoa per group) for three replicates. For membrane-intact spermatozoa, values that differ significantly are indicated by different capitals. For motile spermatozoa, values that differ significantly are indicated by different small letters. For percentage acrosome-detoriated spermatozoa, values that differ significantly are indicated by different numbers of asterisks. Analysis was performed using repeated measure ANOVA with Greenhouse-Heisser and Bonferroni correction; Scheffé post hoc tests were used for pairwise comparisons. 


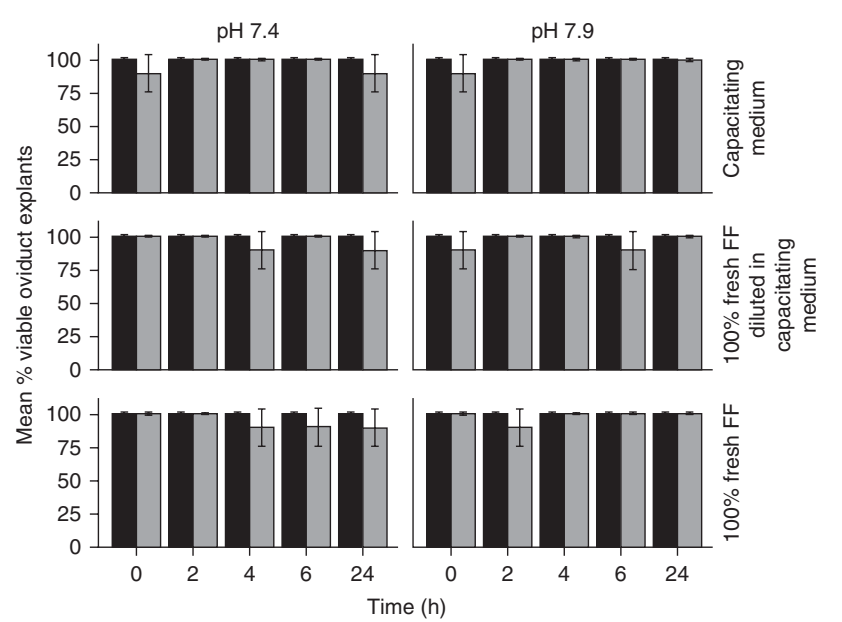

Figure 3 Viability of equine oviduct explants during $24 \mathrm{~h}$ incubation at both $\mathrm{pH} 7.4$ and 7.9 in capacitating medium, $10 \%$ fresh follicular fluid (FF) and $100 \%$ fresh FF. Data represent mean ( \pm s.D.) percent of oviduct explants ( $n=30$ per group) showing ciliary activity (black bars) or intact cell membranes (light grey bars) over three replicates. Statistical analysis was performed using repeated measure ANOVA with Greenhouse-Heisser and Bonferroni correction; Scheffé post hoc tests were used for pairwise comparisons.

(to remove lipids/lipoproteins and lipophilic molecules, including steroids), iv) centrifugation through a $30 \mathrm{kDa}$ filter (filtered FF containing $<30 \mathrm{kDa}$ components) and v) triple treatment (combination of heat inactivation, charcoal treatment and $30 \mathrm{kDa}$ filtration). The fresh FF fraction subjected to $100 \mathrm{kDa}$ filtration, retained the membrane damaging and motility reducing effects on sperm in suspension (Fig. 4). By contrast, heat inactivation, charcoal treatment, $30 \mathrm{kDa}$ filtration and triple treatment all resulted in a complete abolishment of the detrimental effects of FF on sperm in suspension (Fig. 4; $P<0.001)$. All FF fractions that received the former treatments are further referred to as 'treated $\mathrm{FF}^{\prime}$. In this respect, after $6 \mathrm{~h}$ incubation in treated FF (heatinactivated, charcoal-treated, $30 \mathrm{kDa}$ filtration or tripletreated) percentages of motile and PM sperm were $>55 \%$ and $>35 \%$, respectively. For spermatozoa incubated in $100 \mathrm{kDa}$-filtered $\mathrm{FF}$, both total and progressive motility dropped to $<1 \%(P<0.001$; Fig. 4$)$. Thus, the FF component detrimental to sperm integrity is apparently a heat-instable, 30-100 kDa lipophilic entity.

\section{Treated FF induces hyperactive motility responses in suspended sperm at pH 7.9 but not $\mathrm{pH} 7.4$}

As described previously (Leemans et al. 2014), oviductbound spermatozoa undergo intracellular alkalinization and subsequent protein tyrosine phosphorylation in association with a locally elevated $\mathrm{pH}$. While fresh preovulatory FF samples had a standard physiological $\mathrm{pH}$ (7.2 $\pm 0.4 ; n=5$ samples; $P=0.26)$, we found that increasing medium $\mathrm{pH}$ to 7.9 in the presence of treated
FF was sufficient to induce hyperactivation in stallion sperm in suspension that had not had any contact with oviduct tissues (Figs 5 and 6, and Supplementary Figure 1).

At different incubation time points (10 min, 0.5, 1, 1.5, 2, 2.5, 3, 3.5 and $4 \mathrm{~h}$ ), six different CASA parameters associated with hyperactive motility (total motility, progressive motility, lateral head displacement, VCL, STR and LIN) were significantly different between spermatozoa incubated in treated FF at physiological $\mathrm{pH}$ (7.4) and spermatozoa incubated at slightly alkaline $\mathrm{pH}(7.9) \quad(P<0.001)$. With respect to time, sperm suspensions in $\mathrm{pH} 7.9$ treated FF showed a significant rise in ALH and VCL (McPartlin et al. 2009, Loux et al. 2013) within $0.5 \mathrm{~h}$ of incubation; the values were, respectively: heat-inactivated $\mathrm{FF}, 6.3 \pm 0.2 \mu \mathrm{m}$ and $161 \pm 7 \mu \mathrm{m} / \mathrm{s}$; charcoal-inactivated FF, $6.4 \pm 0.1 \mu \mathrm{m}$ and $169 \pm 8 \mu \mathrm{m} / \mathrm{s} ; 30 \mathrm{kDa}$-filtered FF, $6.1 \pm 0.1 \mu \mathrm{m}$ and $159 \pm 14 \mu \mathrm{m} / \mathrm{s}$; triple-treated FF, $6.5 \pm 0.1 \mu \mathrm{m}$ and $159 \pm 13 \mu \mathrm{m} / \mathrm{s}$. These ALH and VCL values remained unchanged until $2.5 \mathrm{~h}$ (Fig. 5 and Supplementary Figure 1). After $2.5 \mathrm{~h}$ of incubation, $\mathrm{ALH}$ and VCL decreased significantly and a marked drop in total motility was observed that indicated a loss of viability (Fig. 5 and Supplementary Figure 1). In contrast, sperm exposed to similarly treated $\mathrm{FF}$ at $\mathrm{pH} 7.4$ remained $\mathrm{PM}$

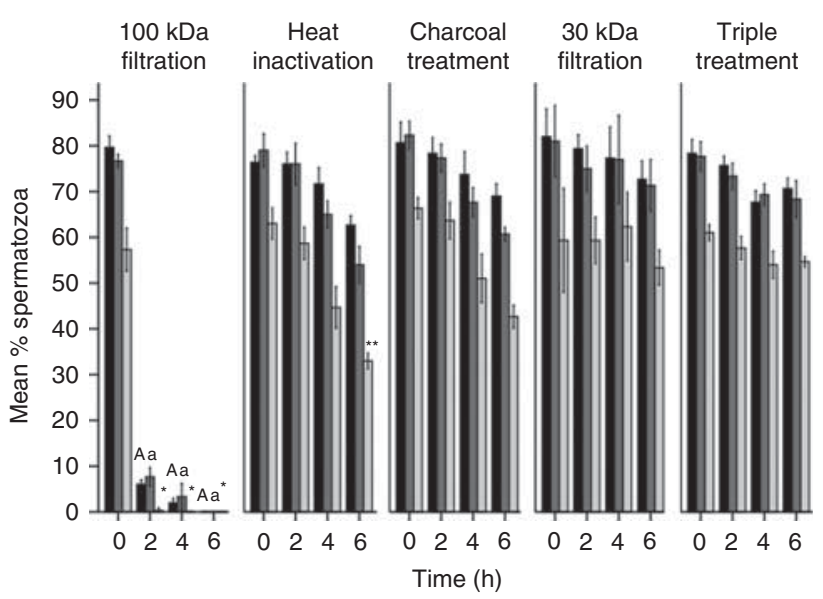

Figure 4 Viability of stallion sperm during a 6 -h incubation in 100\% FF treated in five different ways: 100 tration, heat-inactivation, charcoal treatment, $30 \mathrm{kDa}$ filtration and triple treatment (heat inactivation, charcoal treatment and $30 \mathrm{kDa}$ filtration). Sperm maintained viability during incubation when fresh FF was heat-inactivated, charcoaltreated, filtration through a $30 \mathrm{kDa}$ filter or triple-treated. Data represent mean ( \pm s.D.) percent membrane-intact (black bars), motile (dark grey) or progressively motile (light grey) spermatozoa $(n=200$ spermatozoa per group) for three replicates. For membrane-intact spermatozoa, values that differ significantly are indicated by capitals. For total sperm motility, values that differ significantly are indicated by small letters. For progressive sperm motility, values that differ significantly are indicated by asterisks. Statistical analysis was performed using repeated measure ANOVA with Greenhouse-Heisser and Bonferroni correction; Scheffé post hoc tests were used for pairwise comparisons. 

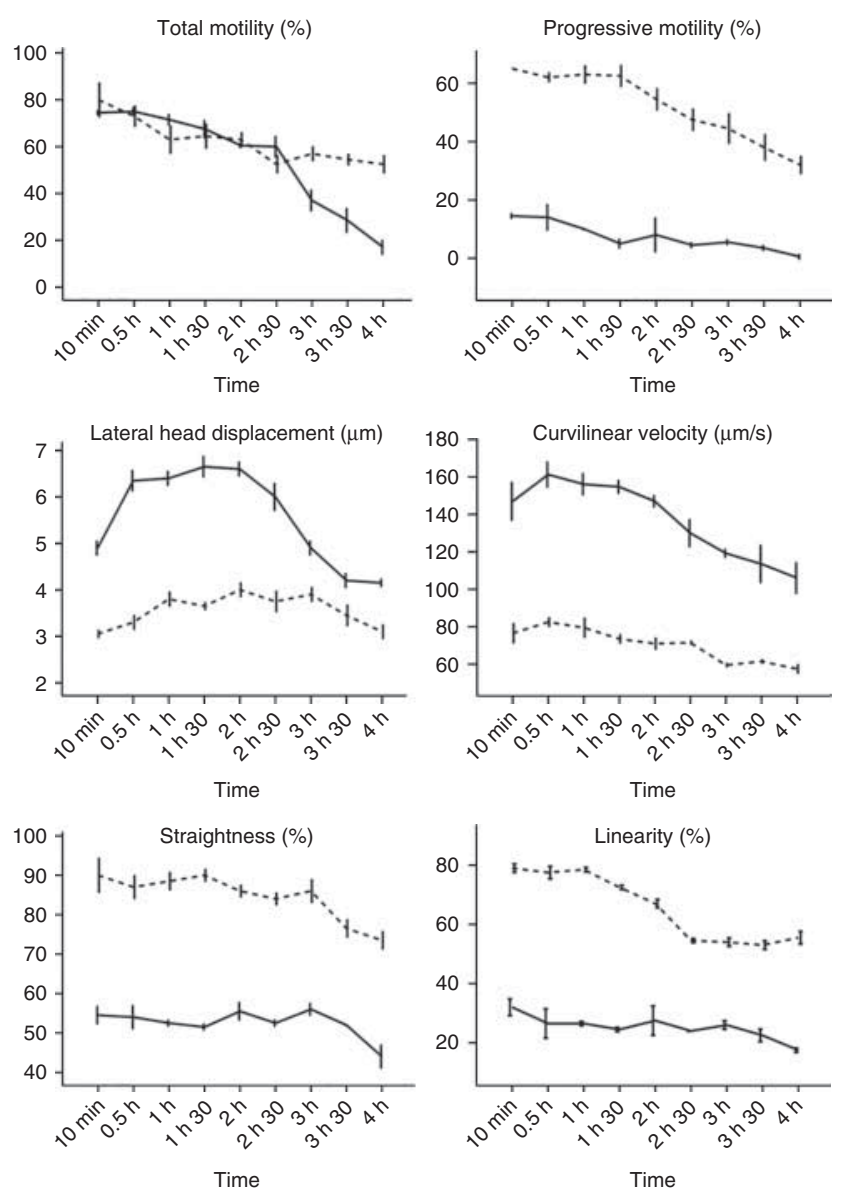

— Heat-inactivated FF; pH 7.9

- - - Heat-inactivated FF; pH 7.4

Figure 5 Evaluation of different motility parameters (\% total motile, $\%$ progressively motile, lateral head displacement, curvilinear velocity, STR and LIN) during $4 \mathrm{~h}$ incubation of stallion sperm suspended in i) $100 \%$ heat-inactivated follicular fluid (FF) at $\mathrm{pH} 7.9$ (full black line) and ii) $100 \%$ heat-inactivated $\mathrm{FF}$ at $\mathrm{pH} 7.4$ (dotted black line).

Heat-inactivated FF stimulated sperm hypermotility at $\mathrm{pH} 7.9$ but not at $\mathrm{pH}$ 7.4. Very similar observations were obtained for charcoal-treated, $30 \mathrm{kDa}$-filtered and triple-treated FF preparations (see Supplementary Figure 1, see section on supplementary data given at the end of this article). Data represent mean ( \pm s.D.) for total (\%) and progressively motile $(\%)$ spermatozoa, amplitude of lateral head displacement $(\mu \mathrm{m})$, curvilinear velocity $(\mu \mathrm{m} / \mathrm{s})$, STR $(\%)$ and LIN $(\%)(n=5$ samples in each group) for three replicates. Analysis was performed using repeated measure ANOVA with Greenhouse-Heisser and Bonferroni correction; Scheffé post hoc tests were used for pairwise comparisons.

with only a slight decrease during the $4 \mathrm{~h}$ incubation (at $0.5 \mathrm{~h} ; \mathrm{ALH}$ and VCL: heat-inactivated FF, $3.3 \pm 0.1 \mu \mathrm{m}$ and $83 \pm 3 \mu \mathrm{m} / \mathrm{s}$; charcoal-inactivated FF, $3.5 \pm 0.1 \mu \mathrm{m}$ and $78 \pm 4 \mu \mathrm{m} / \mathrm{s} ; 30 \mathrm{kDa}$-filtered $\mathrm{FF}, 3.1 \pm 0.2 \mu \mathrm{m}$ and $74 \pm 2 \mu \mathrm{m} / \mathrm{s}$; triple-treated $\mathrm{FF}, 3.5 \pm 0.3 \mu \mathrm{m}$ and $74 \pm$ $1 \mu \mathrm{m} / \mathrm{s})$. In summary, during incubation in all four types of treated $\mathrm{FF}$ at $\mathrm{pH} 7.9$, hyperactivation peaked during $0.5-1 \mathrm{~h}$ and had begun to decrease by $2.5 \mathrm{~h}$ of incubation, whereas similar conditions at $\mathrm{pH} 7.4 \mathrm{did}$ not induce a similar change in motility (Fig. 5 and Supplementary Figure 1).

\section{Treated FF induced concentration-dependent hypermotility responses}

Alkaline $\mathrm{pH}$ (7.9), but not $\mathrm{pH} 7.4$, induced hyperactivated stallion sperm motility in the different undiluted treated FFs, as described above. The dose dependency of the hyperactivating effect was tested further by assessing ALH and VCL in sperm suspensions incubated for $0.5 \mathrm{~h}$ in i) $100 \%$, ii) $50 \%$, iii) $10 \%$ and iv) $0 \%$ treated FF diluted in capacitating medium $(\mathrm{pH} 7.9$ and 7.4).

After $0.5 \mathrm{~h}$ incubation in all 50 and $10 \%$ treated $\mathrm{FF}$ media and capacitating medium ( $100 \%$ or $0 \% \mathrm{FF})$ at $\mathrm{pH}$ 7.9, stallion spermatozoa showed significantly lower hypermotility parameters (ALH and VCL) compared to those exposed to undiluted treated FF $(P<0.001$; Fig. 6).
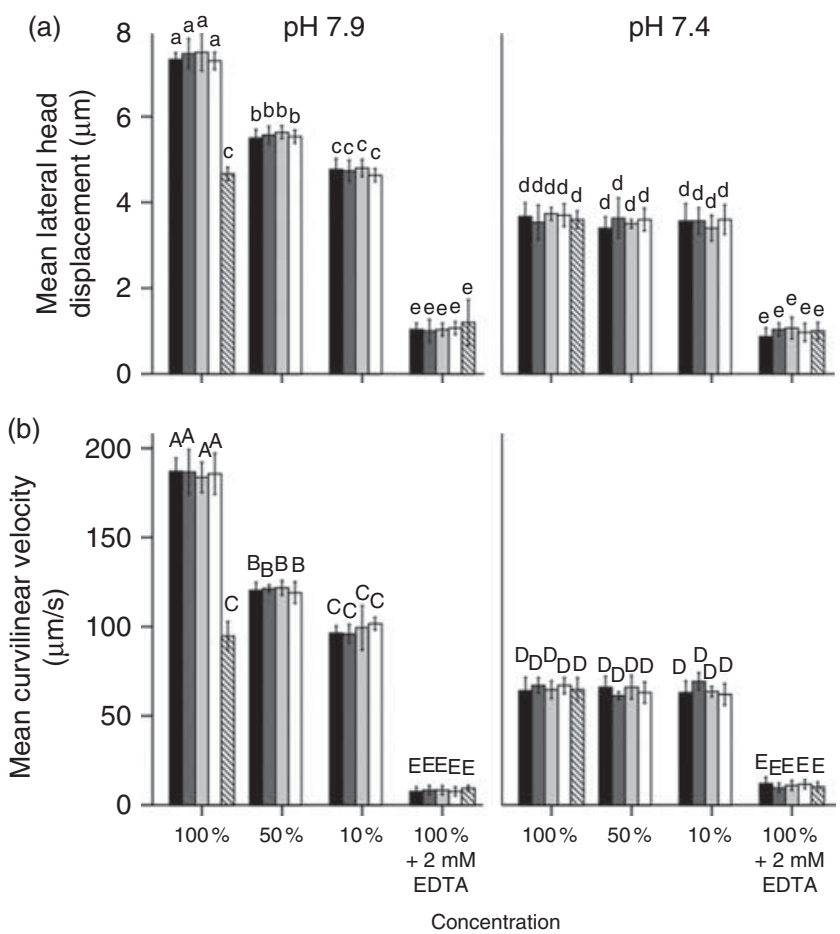

Figure 6 Evaluation of (a) lateral head displacement (ALH) and (b) curvilinear velocity (VCL) as indicators of hyperactivated motility in stallion sperm after $0.5 \mathrm{~h}$ incubation at both $\mathrm{pH} 7.9$ and 7.4 in i) heat-inactivated follicular fluid (FF: black bars), ii) charcoal-treated FF (dark grey bars), iii) $30 \mathrm{kDa}$-filtered FF (light grey bars), iv) triple-treated FF (white bars) and $v)$ capacitating medium $(0 \% \mathrm{FF}=100 \%$ capacitating medium; striped bars). For all FF preparations, 100, 50 and 10\% FF diluted in capacitating medium were assessed; the effect of $\mathrm{Ca}^{2+}$ depletion by $2 \mathrm{mM}$ EDTA was tested for all FF treatments (100\%) ( $n=5$ samples in each group; three replicates). Induction of hyperactivated motility in suspended sperm by the various undiluted FF preparations clearly required external $\mathrm{Ca}^{2+}$ and an elevated medium $\mathrm{pH}$ 7.9; a much lower hyperactivation response was observed in capacitating medium even in the presence of $\mathrm{Ca}^{2+}$ and at $\mathrm{pH}$ 7.9. For lateral head displacement, values that differ significantly are indicated by different small letters; for curvilinear velocity, values that differ significantly are indicated by different capitals. Statistical analysis was performed by repeated measure ANOVA with Greenhouse-Heisser and Bonferroni correction; Scheffé post hoc tests were used for pairwise comparisons. 
Moreover, a significant effect of treated FF concentration was observed; spermatozoa incubated in 50\%-treated FF showed significantly higher ALH and VCL than sperm in $10 \%$-treated $\mathrm{FF}$ or capacitating medium $(0 \%$; $P<0.001$, Fig. 6). Indeed, the ALH and VCL for sperm incubated in $10 \%$-treated FF were very similar to capacitating conditions ( $P=0.11$; Fig. 6).

Similar to the observations for undiluted treated FF (Figs 5 and 6), sperm suspensions incubated in capacitating medium $(0 \%)$ at $\mathrm{pH} 7.9$ showed significantly higher $\mathrm{ALH}$ and $\mathrm{VCL}$ values than sperm in capacitating medium at $\mathrm{pH} 7.4(P<0.001)$; however, the switch from $\mathrm{pH} 7.4$ to 7.9 elicited a much less pronounced effect than in treated FF (Fig. 6). Thus, $\mathrm{pH}$ 7.9-capacitation medium was insufficient to achieve maximal hyperactivated motility. In general, at $\mathrm{pH}$ 7.9, treated FF induced hyperactive motility of equine sperm in a concentration-dependent manner.

\section{Hyperactivated motility induced by undiluted treated $F F$ depends on external $\mathrm{Ca}^{2+}$ and coincides with an increase in cytoplasmic $\mathrm{Ca}^{2+}$ in the sperm head and midpiece}

Hyperactivated motility in mouse sperm (Ren et al. 2001, Carlson et al. 2003) is dependent on the presence and function of the $\mathrm{pH}$-gated CatSper channel, which allows a cytoplasmic $\mathrm{Ca}^{2+}$ influx from the sperm environment. CatSper activation has also been shown to play a role in hyperactivated motility of human sperm (Avidan et al. 2003, Nikpoor et al. 2004, Avenarius et al. 2009). On the other hand, in stallion sperm hyperactivation induced by procaine did not seem to be dependent on external $\mathrm{Ca}^{2+}$, although CatSper1 proteins were shown to be present along the principal piece (Loux et al. 2013). We investigated whether the induction of hyperactivation in stallion sperm by treated $\mathrm{FF}$ at $\mathrm{pH} 7.9$ was dependent on external $\mathrm{Ca}^{2+}$. The addition of $2 \mathrm{mM}$ EDTA to undiluted treated $\mathrm{FF}$ at $\mathrm{pH} 7.9$ led to a marked drop in ALH and $\mathrm{VCL}$, indicating an overall loss in sperm (hyper)motility (Fig. 6). Thus, hyperactivated motility in stallion spermatozoa in undiluted treated FF was clearly dependent on an external $\mathrm{Ca}^{2+}$ source.

Considering that in murine and human sperm, hyperactivated motility is induced by external $\mathrm{Ca}^{2+}$ influx through CatSper channels, we investigated whether hyperactivated motility in stallion sperm coincided with an increased cytoplasmic $\mathrm{Ca}^{2+}$ concentration (monitored by fluo- 4 AM) after $0.5 \mathrm{~h}$ exposure to undiluted treated FF. At pH 7.4, we observed that spermatozoa incubated in treated FF had a similar cytoplasmic $\mathrm{Ca}^{2+}$ signal to control spermatozoa incubated in capacitating medium at $\mathrm{pH} 7.4$ (control; $0 \pm 0 \%$; heat-inactivated FF: $3 \pm 1 \%$, charcoal-treated FF: $2 \pm 1 \%, 30 \mathrm{kDa}$-filtered FF: $3 \pm 2 \%$ and triple-treated FF: $3 \pm 1 \%)$. By contrast, at $\mathrm{pH}$ 7.9 the percentage of spermatozoa with increased cytoplasmic $\mathrm{Ca}^{2+}$ signals was significantly higher in sperm suspensions incubated in treated FF (heatinactivated $\mathrm{FF}, 63 \pm 9$; charcoal-treated $\mathrm{FF}, 71 \pm 9 \%$;

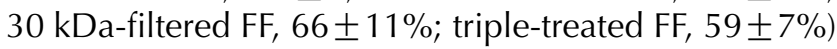
and capacitating medium ( $\mathrm{pH} 7.9$; control, $18 \pm 5 \%$ ), although capacitating medium was much less supportive than treated FF $(P<0.001)$. At $\mathrm{pH} 7.9$ conditions, increased cytoplasmic $\mathrm{Ca}^{2+}$ was mainly observed in the sperm head and midpiece region and coincided with hypermotility (Fig. 7).

\section{Stallion sperm in pH 7.9 treated FF suspensions undergo tail-associated protein tyrosine phosphorylation but, despite the sperm retaining acrosome responsiveness, the acrosome reaction is not induced}

When sperm suspensions were incubated in treated FF with an elevated $\mathrm{pH}$ (7.9), sperm membrane integrity was well preserved after $1 \mathrm{~h}$ of incubation (Fig. 8) with at least $70 \%$ of the sperm population membrane-intact in
$\mathrm{pH} 7.4$

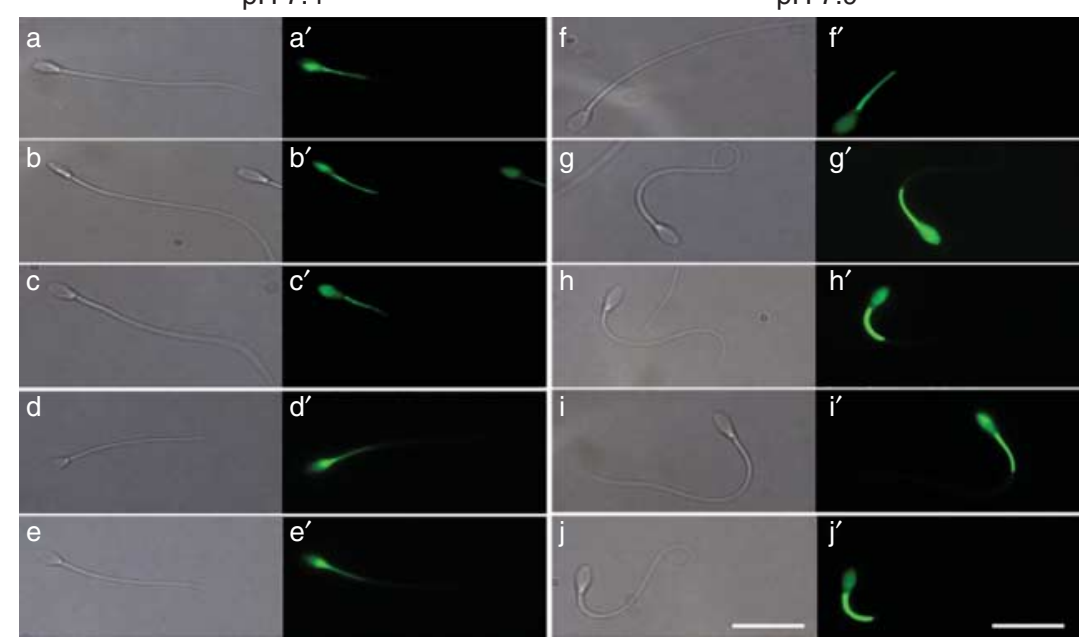

Figure 7 Representative DIC images to illustrate motility patterns of stallion spermatozoa after $1 \mathrm{~h}$ incubation in ( $\mathrm{a}$ and $\mathrm{f}$ ) capacitating medium (control: normal cytoplasmic $\mathrm{Ca}^{2+}$ concentration), (b and g) undiluted heat-inactivated follicular fluid (FF), (c and h) undiluted charcoal-treated FF, (d and i) undiluted 30 kDa-filtered FF and (e and j) undiluted tripletreated FF. All treatments were performed at both $\mathrm{pH}$ 7.4 (a, b, c, d and e) and pH 7.9 (f, g, h, I and j). In all FF preparations at $\mathrm{pH} 7.9$, stallion spermatozoa showed a hyperactive motility pattern, whereas spermatozoa incubated at $\mathrm{pH} 7.4$ or in capacitating medium at $\mathrm{pH}$ 7.9 generally did not. Representative images of fluo-4 AM labelled stallion spermatozoa $\left(a^{\prime}, b^{\prime}, c^{\prime}, d^{\prime}, e^{\prime}, f^{\prime}\right.$, $\mathrm{g}^{\prime}, \mathrm{h}^{\prime}, \mathrm{i}^{\prime}$ and $\left.\mathrm{j}^{\prime}\right)$ incubated under identical conditions, showed that induction of hyperactive motility by FF preparations coincided with an intensified cytoplasmic $\mathrm{Ca}^{2+}$ signal (original magnification, $1000 \times, \operatorname{Bar}=25 \mu \mathrm{m})$. 


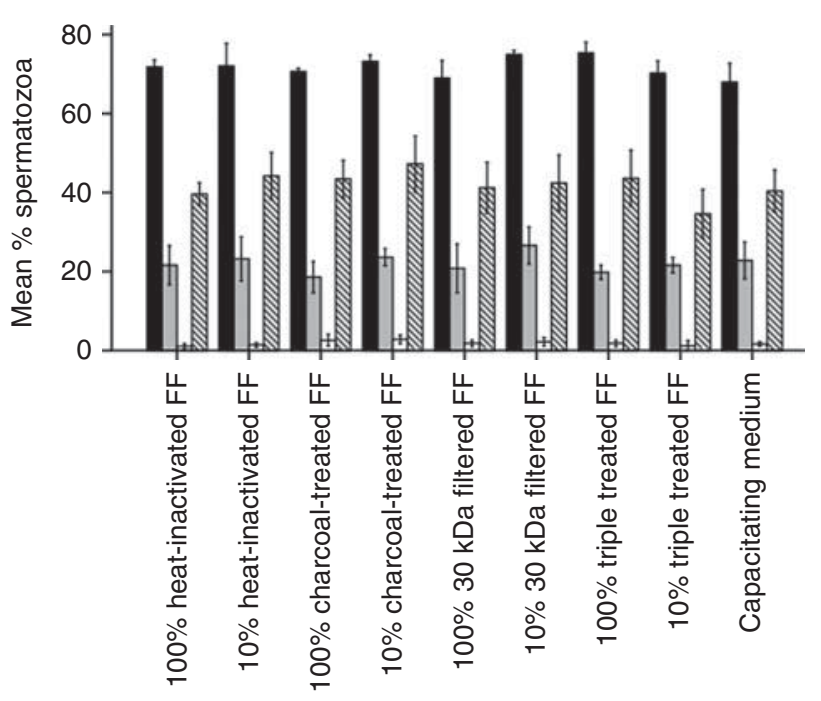

Figure 8 Percentages of membrane-intact, protein tyrosinephosphorylated and acrosome-reacted stallion spermatozoa after $1 \mathrm{~h}$ incubation in 9 different conditions at elevated $\mathrm{pH}$ (7.9): i) 100\% heat-inactivated follicular fluid (FF), ii) $10 \%$ heat-inactivated FF in capacitating medium, iii) $100 \%$ charcoal-treated FF, iv) $10 \%$ charcoaltreated FF in capacitating medium, v) $100 \% 30 \mathrm{kDa}$-filtered FF, vi) $10 \%$ $30 \mathrm{kDa}$-filtered FF in capacitating medium, vii) $100 \%$ triple-treated FF, viii) $10 \%$ triple-treated FF in capacitating medium and ix) capacitating medium. Hyperactivating treatments also induced a $\mathrm{pH}$-dependent tail-associated protein tyrosine phosphorylation, although the acrosome reaction was not stimulated. The percentage of acrosomereacted stallion spermatozoa after $1 \mathrm{~h}$ incubation under identical treated-FF conditions at $\mathrm{pH} 7.9$ and followed by $30 \mathrm{~min}$ exposure to calcium ionophore A23187 was also examined. While treated FF did not induce the acrosome reaction, the sperm were still able to undergo acrosomal exocytosis in response to calcium ionophore. Data represent mean ( \pm s.D.) percent membrane-intact (black bars), protein tyrosinephosphorylated (dark grey bars) and acrosome-reacted spermatozoa before (white bars) and after (hatched bars) calcium ionophore A23187 exposure ( $n=5$ sperm suspensions in each group) for three replicates. Analysis was performed using one-way ANOVA, with post hoc Scheffé tests for pairwise comparisons.

all groups. More than $18 \%$ of the sperm showed tailassociated protein tyrosine phosphorylation, but the cells did not undergo acrosomal exocytosis in any of the treatment groups. However, sperm suspensions incubated in treated FF were still able to undergo an acrosome reaction following exposure to calcium ionophore A23187; indeed, acrosomal exocytosis was induced in more than $40 \%$ of the spermatozoa incubated in treated FF (Fig. 8). In general, at $\mathrm{pH} \mathrm{7.9,} \mathrm{the}$ percentages of membrane-intact, protein tyrosine phosphorylated and acrosome-intact sperm were independent of the FF concentration (100 or $10 \%)(P>0.18$ for all comparisons; Fig. 8).

\section{Hyperactivation induced the release of a very limited number of spermatozoa from oviduct explants}

In cattle, during the process of in vitro capacitation oviduct-bound spermatozoa will release from the epithelium in a hyperactivated state (Lefebvre \& Suarez 1996). Since we found that treated FF can trigger sperm hyperactivation, we wanted to determine whether it would induce oviduct-bound sperm to release. To this end, sperm-oviduct explant binding was allowed under non-capacitating conditions ( $\sim 120000$ bound spermatozoa $/ \mathrm{mm}^{2}$ ) and, subsequently, these sperm-oviduct explants were transferred to capacitating/hyperactivating media. Alternatively, sperm-oviduct explants were incubated in the different treated FFs (heat-inactivated, charcoal-treated, $30 \mathrm{kDa}$-filtered and triple treatment). In addition, capacitation media containing $5 \mathrm{mM}$ procaine and/or at $\mathrm{pH} 7.9$ were compared to $\mathrm{pH} 7.4$ capacitation conditions. After $2 \mathrm{~h}$ of incubation, none of the conditions resulted in significant sperm release considering the total number of sperm bound per $\mathrm{mm}^{2}$ (Fig. 9b). However, in all conditions inducing hyperactivated sperm motility in previous experiments, a small number of hyperactivated spermatozoa (70-120 spermatozoa per oviduct explant; Fig. 9a) were released from the oviduct explants (Supplementary Videos 1 and 2, see section on supplementary data given at the end of this article). We conclude that the induction of sperm hyperactivated motility did not induce a massive release of capacitated spermatozoa from the oviduct epithelium. However, these findings may reflect earlier suggestions that only a very small population of spermatozoa is able to release from their binding and approach the oocyte at the time of fertilization, to reduce the risk of polyspermy (Hunter 1993, 2005a, 2008).

\section{Properties of sperm released from the oviduct}

After release of hyperactivated spermatozoa from the oviduct epithelium triggered by $\mathrm{pH} 7.9$ treated $\mathrm{FF}$, at least $85 \%$ of the released spermatozoa were membraneintact, more than $45 \%$ showed tail-associated protein tyrosine phosphorylation, whereas hardly any had undergone acrosomal exocytosis. Similar results were achieved in the presence of procaine (at pH 7.4 and 7.9) except that tail-associated protein tyrosine phosphorylation rates were much lower $(8 \%)$ in the $\mathrm{pH} 7.4$ procaine condition (Fig. 10).

\section{Discussion}

It is generally believed that mammalian sperm, including stallion spermatozoa, have to follow a regulated sequence of events during capacitation in vivo in order to achieve fertilizing capacity (Yanagimachi 1994). Ejaculated spermatozoa travel through the mare's reproductive tract to the oviduct, where a sperm reservoir is formed by viable, non-capacitated spermatozoa (Boyle et al. 1987, Hunter 2012). In a previous study, we reported that equine oviduct epithelial cells harvested close to the time of ovulation contain large 

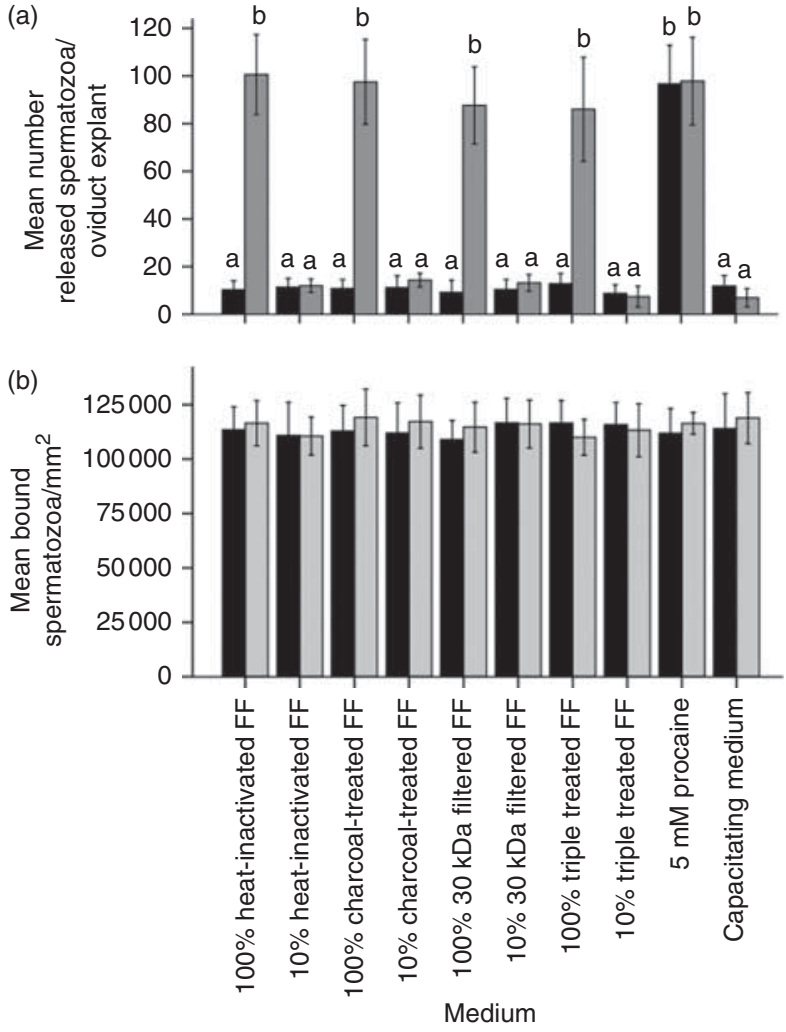

Figure 9 (a) Mean number of stallion spermatozoa released per oviduct explant and (b) mean spermatozoa bound per $\mathrm{mm}^{2}$ epithelium, assessed after $2 \mathrm{~h}$ incubation in i) 100\% heat-inactivated follicular fluid (FF) ii) $10 \%$ heat-inactivated FF in capacitating medium iii) $100 \%$ charcoal treated FF iv) $10 \%$ charcoal treated FF in capacitating medium v) $100 \% 30 \mathrm{kDa}$-filtered $\mathrm{FF}$ vi) $10 \% 30 \mathrm{kDa}$-filtered FF in capacitating medium, vii) $100 \%$ triple-treated $\mathrm{FF}$, viii) $10 \%$ triple-treated $\mathrm{FF}$ in capacitating medium, ix) $5 \mathrm{mM}$ procaine in capacitating medium and $\mathrm{x}$ ) capacitating medium. Each incubation was performed at $\mathrm{pH} 7.4$ (black bars) and pH 7.9 (light grey). Only a modest release of oviduct bound spermatozoa was observed in the various hyperactivating conditions. Data represent mean ( \pm s.D.) bound spermatozoa per $\mathrm{mm}^{2}$ ( $n=20$ per group) for three replicates. Analysis was performed using repeated measure ANOVA with Greenhouse-Heisser and Bonferroni correction, with Scheffé post hoc tests for pairwise comparisons.

secretory vesicles with an elevated $\mathrm{pH}$. Moreover, protein tyrosine phosphorylation in the tails of spermatozoa bound to these oviduct epithelial cells was associated with contemporaneous intracellular alkalization of the spermatozoa and vesicle discharge (Leemans et al. 2014). In anticipation of oocyte arrival, spermatozoa in which capacitation has been initiated need to be released from the oviduct epithelium, an event that may require the acquisition of hyperactivated motility (Hunter et al. 1999, Suarez 2008b). Released capacitated/hyperactivated spermatozoa will subsequently migrate to the isthmus-ampullary junction to fertilize the mature oocyte (Publicover et al. 2007, Lishko et al. 2011). Sperm release from the oviduct epithelium by hyperactivation, and subsequent acrosome reaction after contacting the extracellular vestments of the oocyte has, however, not yet been reliably achieved in vitro in the horse, but may be crucial to obtaining reliable fertilization in vitro. Until now, only exposure to procaine has been shown to reliably induce hyperactivated motility in stallion spermatozoa (McPartlin et al. 2009, Ortgies et al. 2012, Loux et al. 2013), and this was independent of CatSper-related $\mathrm{Ca}^{2+}$ influx (Loux et al. 2013). In the current study, we induced hyperactivation of stallion spermatozoa using slightly alkaline $(\mathrm{pH} 7.9)$ undiluted treated FF (i.e., either heat-inactivated, charcoal-treated, $30 \mathrm{kDa}$-filtered or all three to neutralize a spermicidal factor in FF). In contrast to procaineinduced hyperactivation (Loux et al. 2013), we found that the treated FF induced hyperactivation in stallion sperm was dependent on external $\mathrm{Ca}^{2+}$. Under the hyperactivating conditions at $\mathrm{pH} 7.9$, a significant rise in cytoplasmic $\mathrm{Ca}^{2+}$ levels was observed predominantly in the sperm head and midpiece. The hyperactivated sperm remained membrane- and acrosome-intact and showed protein tyrosine phosphorylation, i.e., the cardinal signs of sperm capacitation without sperm deterioration. Interestingly, sperm bound to oviduct epithelium were not released en masse into the lumen after such

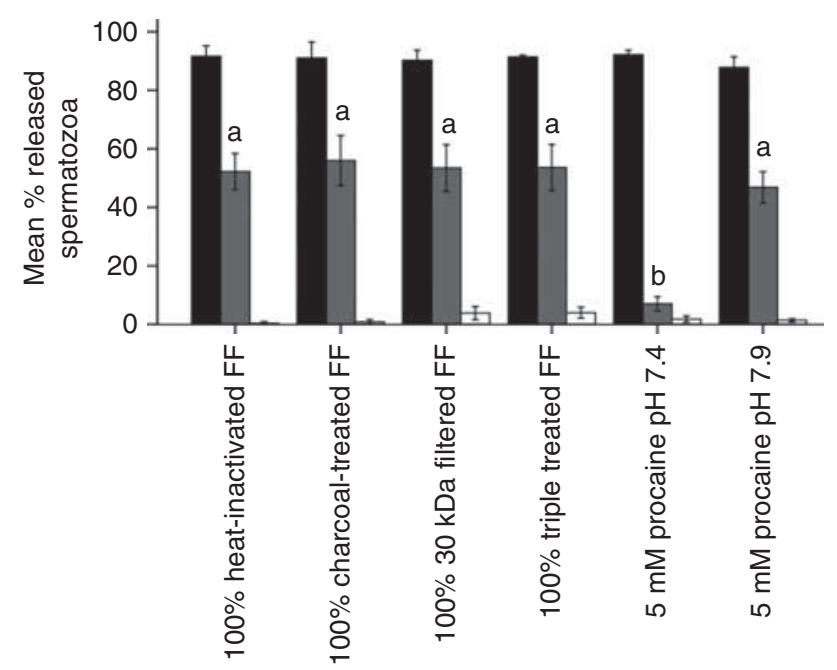

Figure 10 Percentages of membrane-intact, protein tyrosine-phosphorylated and acrosome-reacted stallion spermatozoa following release from oviduct explant binding during $2 \mathrm{~h}$ incubation in i) $100 \%$ heat-inactivated $\mathrm{FF}$, ii) 100\% charcoal-treated FF, iii) 100\% $30 \mathrm{kDa}$ filtered $\mathrm{FF}$, iv) $100 \%$ triple-treated $\mathrm{FF}$, v) $5 \mathrm{mM}$ procaine diluted in capacitating medium $\mathrm{pH} 7.4$ and vi) $5 \mathrm{mM}$ procaine diluted in capacitating medium $\mathrm{pH} 7.9$ capacitating medium. Data represent mean ( \pm s.D.) \% membrane-intact (black bars), \% protein tyrosinephosphorylated (dark grey bars) and \% acrosome-reacted spermatozoa (white bars). Data represent mean ( \pm s.D.) percentage of hyperactivated (black bars), membrane-intact (dark grey bars), protein tyrosinephosphorylated (light grey bars) and acrosome-reacted (white bars) spermatozoa ( $n=20$ oviduct explants in each group) for three replicates. For protein tyrosine-phosphorylated spermatozoa, values that differ significantly are indicated by different small letters. Analysis was performed using one-way ANOVA; Scheffé post hoc tests were performed for pairwise comparisons. 
treatments. Instead, only a very small population was released, although a large proportion of these cells did show a capacitation-like phenotype in terms of motility, tyrosine phosphorylation and membrane integrity. In short, a combined effect of elevated environmental $\mathrm{pH}$, external $\mathrm{Ca}^{2+}$ and unidentified FF factor(s) appear to trigger hyperactivation of stallion spermatozoa, whereas the tail-associated protein tyrosine phosphorylation response appears to depend only on $\mathrm{pH}$.

By testing a variety of FF treatments, we were able to demonstrate that sperm integrity was maintained in heatinactivated, charcoal-treated, $30 \mathrm{kDa}$-filtered or tripletreated FF whereas untreated fluid or a $<100 \mathrm{kDa}$ filtrate had a sperm-deteriorating effect. This implies that the FF component that compromises sperm viability has a size between 30 and $100 \mathrm{kDa}$, but can be neutralized by hea inactivation or charcoal treatment. Heat inactivation causes the breakdown of tertiary and quaternary protein structures and could, for example, neutralize complement factors that might be activated under in vitro conditions due to exposure to air (Yoo et al. 2013). Charcoal treatment extracts the lipid fraction including steroids and lipoproteins (Cheng et al. 1998). Based on these results, we hypothesize that the sperm-deteriorating factor is a steroid or lipid bound to a protein. Further research is required to elucidate which component of fresh, air-exposed FF exerts a detrimental effect on sperm in vitro.

Interestingly, rather than stimulating sperm deterioration, the undiluted treated FF (heat-inactivated, charcoal-treated, $30 \mathrm{kDa}$-filtered or triple-treated) was able to induce hyperactivation of stallion spermatozoa in suspension at $\mathrm{pH}$ 7.9. A similar trend was also observed for spermatozoa incubated in capacitating conditions at $\mathrm{pH} 7.9$, although the hyperactivated motility response was much lower than in treated FF. However, we have not yet identified the component(s) of equine FF that triggers hyperactivated sperm motility. Possible heatresistant, hydrophilic candidates $(<30 \mathrm{kDa})$ in FF include carbohydrates, small heat-resistant proteins and electrolytes. Theoretically, our results suggest that i) components of FF may be involved in sperm hyperactivation in the horse oviduct or that ii) undiluted treated FF mimics capacitation conditions that are induced in vivo by oviduct secretions in the periovulatory period. Additionally, the fact that hyperactivated motility required a slightly alkaline $\mathrm{pH}$, which was not a feature of pre-ovulatory FF ( $\mathrm{pH} \pm 7.2)$, supports our hypothesis that, in the narrow and tortuous oviduct lumen, alkalinization at the sperm-oviduct interface results from oviduct secretory activity at the time of ovulation (Leemans et al. 2014), which in turn triggers an intracellular $\mathrm{pH}$ rise in oviduct-bound stallion spermatozoa and provokes protein tyrosine phosphorylation. In the present study, we additionally showed that FF components have a significant effect on sperm hyperactivation.
Undiluted treated FF stimulated the biggest increase in $\mathrm{ALH}$ and $\mathrm{VCL}$, whereas a more muted hyperactivation response was observed when sperm were incubated in 50 and $10 \% \mathrm{FF}$ ( $\mathrm{pH}$ 7.9) or in capacitating medium alone $(\mathrm{pH}$ 7.9). These observations demonstrate a concentration-dependent effect of the unidentified FF factor(s) on stallion sperm hyperactivation.

The results of this study highlight that there is as yet no defined capacitating medium for stallion sperm. In this respect, it is pertinent that capacitating conditions that reliably and repeatedly support equine IVF have not yet been reported. As concluded by McPartlin et al. (2009), a major deficit of current capacitating media appears to be the ability to induce hyperactivated motility in stallion sperm. Besides the fact that an elevated $\mathrm{pH}$ seems to be critical, further research needs to focus on a systematic investigation of components in treated FF compared to capacitating medium. Comparing the sperm hyperactivation-supporting conditions among various mammals, we assume that this process is not well conserved. In humans, it has been reported that factors in $\mathrm{FF}$, and secreted by cumulus cells, can initiate hyperactivation (Fetterolf et al. 1994a, b, Yao et al. 2000). In the hamster (Yanagimachi 1969) and rabbit (Harper 1973a,b), contact with FF also provokes sperm hyperactivation. The key elements of these ovulation-associated products on CatSper-induced hypermotility are bicarbonate, which supports an alkaline intracellular $\mathrm{pH}$, and progesterone (Harper et al. 2004, Publicover et al. 2007, Lishko et al. 2011, Strunker et al. 2011). On the other hand, various studies in rabbit (Overstreet \& Cooper 1979), mouse (Suarez \& Osman 1987) and large farm animals (Hunter 2005b, 2008) with relatively long pre-ovulatory periods have indicated that sperm hyperactivation and subsequent sperm-oviduct release starts in a controlled manner shortly before ovulation. This implies that the trigger to hyperactivation must be derived from oviductal fluid or by contact with oviduct epithelia and not from components resulting from ovulation, such as FF or the cumulus-oocyte-complex. The active components in the oviduct that induce CatSper-induced hypermotility also appear to differ between species. In the mouse, bicarbonate is the main trigger for hyperactivation (Neill \& Olds-Clarke 1987). In bull sperm, Marquez \& Suarez (2007) concluded that an increased external pH was the primary signal for sperm hyperactivation. Bull sperm can also achieve full fertilizing capacity after contact with heparin and other sulfated glycoconjugates. These molecules are abundantly present in oviductal and $\mathrm{FF}$, and induce release of sperm adhering to oviduct epithelium monolayers in vitro by increasing their flagellar beat (Talevi \& Gualtieri 2001, Gualtieri et al. 2005, Therien et al. 2005). Heparin-like molecules also induce hyperactivation of free-swimming sperm (Chamberland et al. 2001). The biological hyperactivating triggers for stallion sperm have not been investigated. 
The experiments to examine the induction of hyperactivation by undiluted treated FF showed clearly that hyperactivated motility triggered in this way depends on extracellular $\mathrm{Ca}^{2+}$. Surprisingly, these results are in contrast to procaine-induced hyperactivated motility for which external $\mathrm{Ca}^{2+}$ was not required (Loux et al. 2013). In mice, hyperactivated sperm motility during capacitation is provoked by $\mathrm{Ca}^{2+}$ influx through $\mathrm{pH}$-gated cationic CatSper channels, located along the principal piece of the sperm flagellum (Quill et al. 2001, Ren et al. 2001, Carlson et al. 2003, Quill et al. 2003, Suarez 2008b, Chang \& Suarez 2011). In humans, mutations in CATSPER genes have similarly been associated with infertility and abnormal sperm motility (Avidan et al. 2003, Nikpoor et al. 2004, Avenarius et al. 2009). Whether our undiluted inactivated FF conditions induce hyperactivated motility by $\mathrm{Ca}^{2+}$ influx via CatSper channels or via other $\mathrm{Ca}^{2+}$ permeable ion channels (voltage-gated $\mathrm{Ca}^{2+}$ channels $(\mathrm{CaVs})$, transient receptor potential channels, cyclic nucleic gated channels or pkD2 cation channels (Li et al. 2007, Suarez 2008b) remains to be investigated, but some important elements indicate that functional $\mathrm{pH}$-gated cationic CatSper channels are likely to be involved. Firstly, CatSper1 proteins have been shown to be present along the principal piece of stallion sperm (Loux et al. 2013). Additionally, we showed that the initiation of hyperactivated motility was a specific alkaline $\mathrm{pH}$ dependent event. Moreover, we showed that FF-induced hyperactivated motility of stallion sperm depends on external $\mathrm{Ca}^{2+}$. These observations favour the hypothesis that CatSper channels are involved in capacitation-related hyperactivated motility in the horse. This hypothesis was further supported by the increased cytoplasmic $\mathrm{Ca}^{2+}$ signal in sperm incubated in treated $\mathrm{FF}$ at $\mathrm{pH}$ 7.9. After $1 \mathrm{~h}$ incubation under hyperactivating conditions, Fluo-4 AM labelling appeared mainly in the sperm head and midpiece, but was very weak in the principal piece. It is interesting that a marked $\mathrm{Ca}^{2+}$ signal was not observed in the principal piece, where the CatSper channels are meant to be located. In mice, Xia \& Ren (2009) showed that the $\mathrm{Ca}^{2+}$ signal acquired during incubation in hyperactivating conditions rapidly propagated from the principal piece to the sperm head. Moreover, it has been hypothesized that the external $\mathrm{Ca}^{2+}$ influx through the CatSper channels subsequently induces a $\mathrm{Ca}^{2+}$ release from the intracellular cytoplasmic $\mathrm{Ca}^{2+}$ stores or the $\mathrm{RNE}$, involving inositol triphosphate receptors located near the sperm neck (' $\mathrm{Ca}^{2+}$-induced $\mathrm{Ca}^{2+}$ release') (Ho \& Suarez 2003, Publicover et al. 2007, Bedu-Addo et al. 2008, Costello et al. 2009, Olson et al. 2011). This may help explain why a significant cytoplasmic $\mathrm{Ca}^{2+}$ rise is seen in the sperm head and midpiece.

In this study, the acrosome reaction was not induced during sperm incubation in the treated FF samples, even though incubated sperm were still capable of acrosomal exocytosis. Previously, progesterone was shown to be the key factor inducing the acrosome reaction in FF-exposed stallion sperm, and did so without affecting sperm viability and motility (Cheng et al. 1998, Rodriguez et al. 2001). It is also known that steroid hormones, including progesterone, bind to albumin in blood serum (Burton \& Westphal 1972) and FF (Cook et al. 1977). We propose that removing the spermdeteriorating component in FF by various treatments (heat-inactivation, charcoal treatment and $30 \mathrm{kDa}$ filtration) coincidentally inactivated or otherwise extracted this steroid-protein complex. In support of this hypothesis, Cheng et al. (1998) demonstrated that charcoal treatment, to remove progesterone from FF, also removed the stimulus for stallion sperm to undergo the acrosome reaction.

In the first experiment, we showed that contact with reproductive fluids and cells that the sperm would expect to contact in the sperm reservoir during the periovulatory period, did not induce release of stallion sperm from oviduct epithelium. In the light of our subsequent hypothesis that treated FF preparations with elevated $\mathrm{pH}$ mimic the physiological condition in the oviduct during the peri-ovulatory period, we need to consider the possibility that, in vitro, the collected pre- and postovulatory oviductal fluids do not represent the in vivo condition since the oviductal fluid was i) flushed using capacitating medium and was thus considerably diluted whereby important molecules would have been diluted; or ii) the $\mathrm{pH}$ of oviductal fluid may have been decreased by this method of collection. However, given the very limited amount of free fluid present in the oviduct, it was impossible to collect a usable amount in pure form. Furthermore, in the final experiment we observed that even the induction of hyperactivated motility by treated FF or procaine did not induce massive sperm release. However, in terms of the absolute number of spermatozoa, hyperactivating conditions (the combined effects of $\mathrm{FF}$ factors and elevated $\mathrm{pH}$ or procaine) induced a limited release of sperm bound to oviduct explants. We can suggest two reasons why the released sperm fraction was so small: i) just like sperm-oviduct binding, spermoviduct release is a sperm quality selection mechanism that ensures an optimum chance of the mature oocyte being fertilized by a suitable sperm; ii) Suarez (1998, 2001) hypothesized that close coordination of plasma membrane changes and the induction of hyperactivated motility is a requirement for sperm release from the oviduct epithelium. Our FF hyperactivating conditions may have lacked appropriate triggers for capacitationrelated plasma membrane changes. On the other hand, Hunter (1993, 2005a, 2008) showed that in vivo at the time of fertilization only a very small number of capacitated, hyperactivated oviduct-bound spermatozoa are able to escape from the oviduct epithelium and reach the cumulus-oocyte complex at the isthmic-ampullary junction (low sperm:egg ratios). The biological relevance can be viewed in the context of a reduced risk of 
multiple oocyte penetration or polyspermy. Moreover, Hunter $(1996,2012)$ reported that, in contrast to the tight regulation during the peri-ovulatory period, during the post-ovulatory period increasing numbers of spermatozoa were able to detach from the oviduct. This does not interfere with fertilization because a stable block to polyspermy is rapidly established in fertilized, activated oocytes. In our experiments, we did not observe this enhanced release by ovulation associated factors. Two possible reasons can explain why: i) we only used oviducts from cyclic mares in the pre-ovulatory stage or ii) our FF conditions did not support hyperactivation for long enough, given the loss of sperm viability and motility after $2.5 \mathrm{~h}$ incubation. In summary, these observations indicate that the induction of hyperactivated sperm motility was not sufficient to release large numbers of sperm from oviduct binding; however, a small but significant population did release.

In conclusion, we have previously shown that stallion sperm acquire important hallmarks of capacitation (elevated intracellular $\mathrm{pH}$ and tail-associated protein tyrosine phosphorylation) after binding to alkaline vesicle-containing pre-ovulatory oviduct epithelial cells. In the present study, we found that contact with treated FF components induces hyperactivated sperm motility using a mechanism that depends on an elevated $\mathrm{pH}$ and extracellular $\mathrm{Ca}^{2+}$; however, this induction of hyperactivation triggers only a modest sperm release from the oviduct epithelium. It is therefore likely that other factors that support aspects of capacitation and hyperactivation are needed to complete the cascade that prepares the spermatozoa for the acrosome reaction and penetration of the zona pellucida.

\section{Supplementary data}

This is linked to the online version of the paper at http://dx.doi. org/10.1530/REP-15-0178.

\section{Declaration of interest}

The authors declare that there is no conflict of interest that could be perceived as prejudicing the impartiality of the research reported.

\section{Funding}

This work was supported by the Agency for Innovation in Science and Technology (IWT-Flanders; grant number 101521).

\section{Acknowledgements}

The authors wish to thank Petra Van Damme and Isabel Lemahieu for their excellent technical assistance. Fresh stallion semen was kindly provided by the clinic of Reproduction and Obstetrics of Large Animals, Merelbeke, Belgium.

\section{References}

Aalberts M, Sostaric E, Wubbolts R, Wauben MW, Nolte-'t Hoen EN, Gadella BM, Stout TA \& Stoorvogel W 2013 Spermatozoa recruit prostasomes in response to capacitation induction. Biochimica et Biophysica Acta 1834 2326-2335. (doi:10.1016/j.bbapap.2012.08.008)

Austin CR 1952 The capacitation of the mammalian sperm. Nature 170 326. (doi:10.1038/170326a0)

Avenarius MR, Hildebrand MS, Zhang Y, Meyer NC, Smith LL, Kahrizi K, Najmabadi H \& Smith RJ 2009 Human male infertility caused by mutations in the CATSPER1 channel protein. American Journal of Human Genetics 84 505-510. (doi:10.1016/j.ajhg.2009.03.004)

Avidan N, Tamary H, Dgany O, Cattan D, Pariente A, Thulliez M, Borot N, Moati L, Barthelme A, Shalmon L et al. 2003 CATSPER2, a human autosomal nonsyndromic male infertility gene. European Journal of Human Genetics 11 497-502. (doi:10.1038/sj.ejhg.5200991)

Bedu-Addo K, Costello S, Harper C, Machado-Oliveira G, Lefievre L, Ford C, Barratt C \& Publicover S 2008 Mobilisation of stored calcium in the neck region of human sperm - a mechanism for regulation of flagellar activity. International Journal of Developmental Biology 52 615-626. (doi:10.1387/ijdb.072535kb)

Boyle MS, Cran DG, Allen WR \& Hunter RH 1987 Distribution of spermatozoa in the mare's oviduct. Journal of Reproduction and Fertility. Supplement 35 79-86.

Burton RM \& Westphal U 1972 Steroid hormone-binding proteins in blood plasma. Metabolism 21 253-276. (doi:10.1016/0026-0495(72)90048-0)

Carlson AE, Westenbroek RE, Quill T, Ren D, Clapham DE, Hille B, Garbers DL \& Babcock DF 2003 CatSper1 required for evoked $\mathrm{Ca}^{2+}$ entry and control of flagellar function in sperm. PNAS $10014864-14868$. (doi:10.1073/pnas.2536658100)

Chamberland A, Fournier V, Tardif S, Sirard MA, Sullivan R \& Bailey JL 2001 The effect of heparin on motility parameters and protein phosphorylation during bovine sperm capacitation. Theriogenology 55 823-835. (doi:10.1016/S0093-691X(01)00446-0)

Chang MC 1951 Fertilizing capacity of spermatozoa deposited into the fallopian tubes. Nature 168 697-698. (doi:10.1038/168697b0)

Chang H \& Suarez SS 2011 Two distinct $\mathrm{Ca}(2+)$ signaling pathways modulate sperm flagellar beating patterns in mice. Biology of Reproduction 85 296-305. (doi:10.1095/biolreprod.110.089789)

Cheng FP, Fazeli AR, Voorhout WF, Tremoleda JL, Bevers MM \& Colenbrander B 1998 Progesterone in mare follicular fluid induces the acrosome reaction in stallion spermatozoa and enhances in vitro binding to the zona pellucida. International Journal of Andrology 21 57-66. (doi:10.1046/j.1365-2605.1998.00096.x)

Cook B, Hunter RH \& Kelly AS 1977 Steroid-binding proteins in follicular fluid and peripheral plasma from pigs, cows and sheep. Journal of Reproduction and Fertility 51 65-71. (doi:10.1530/jrf.0.0510065)

Costello S, Michelangeli F, Nash K, Lefievre L, Morris J, MachadoOliveira G, Barratt C, Kirkman-Brown J \& Publicover S $2009 \mathrm{Ca}^{2+}$ stores in sperm: their identities and functions. Reproduction 138 425-437. (doi:10.1530/REP-09-0134)

Demott RP \& Suarez SS 1992 Hyperactivated sperm progress in the mouse oviduct. Biology of Reproduction 46 779-785. (doi:10.1095/biolreprod46.5.779)

De Pauw IM, Van Soom A, Laevens H, Verberckmoes S \& de Kruif A 2002 Sperm binding to epithelial oviduct explants in bulls with different nonreturn rates investigated with a new in vitro model. Biology of Reproduction 67 1073-1079. (doi:10.1095/biolreprod67.4.1073)

Fetterolf PM, Jurisicova A, Tyson JE \& Casper RF 1994a Conditioned medium from human cumulus oophorus cells stimulates human sperm velocity. Biology of Reproduction 51 184-192. (doi:10.1095/biolreprod51.2.184)

Fetterolf PM, Sutherland CS, Josephy PD, Casper RF \& Tyson JE 1994b Preliminary characterization of a factor in human follicular fluid that stimulates human spermatozoa motion. Human reproduction 9 1505-1511.

Flechon JE \& Hunter RH 1981 Distribution of spermatozoa in the uterotubal junction and isthmus of pigs, and their relationship with the luminal epithelium after mating: a scanning electron microscope study. Tissue \& Cell 13 127-139. (doi:10.1016/0040-8166(81)90043-4)

Giard DJ 1987 Routine heat inactivation of serum reduces its capacity to promote cell attachment. In Vitro Cellular \& Developmental Biology 23 691-697. (doi:10.1007/BF02620982) 
Gonzalez-Fernandez L, Macias-Garcia B, Velez IC, Varner DD \& Hinrichs K 2012 Calcium-calmodulin and pH regulate protein tyrosine phosphorylation in stallion sperm. Reproduction 144 411-422. (doi:10. 1530/REP-12-0067)

Gualtieri R, Boni R, Tosti E, Zagami M \& Talevi R 2005 Intracellular calcium and protein tyrosine phosphorylation during the release of bovine sperm adhering to the fallopian tube epithelium in vitro. Reproduction $\mathbf{1 2 9}$ 51-60. (doi:10.1530/rep.1.00374)

Harper MJ 1973a Stimulation of sperm movement from the isthmus to the site of fertilization in the rabbit oviduct. Biology of Reproduction 8 369-377.

Harper MJ $1973 b$ Relationship between sperm transport and penetration of eggs in the rabbit oviduct. Biology of Reproduction 8 441-450.

Harper CV, Barratt CL \& Publicover SJ 2004 Stimulation of human spermatozoa with progesterone gradients to simulate approach to the oocyte. Induction of $[\mathrm{Ca}(2+)](\mathrm{i})$ oscillations and cyclical transitions in flagellar beating. Journal of Biological Chemistry 279 46315-46325. (doi:10.1074/jbc.M401194200)

Ho HC \& Suarez SS 2003 Characterization of the intracellular calcium store at the base of the sperm flagellum that regulates hyperactivated motility. Biology of Reproduction 68 1590-1596. (doi:10.1095/biolreprod.102. 011320)

Ho HC, Granish KA \& Suarez SS 2002 Hyperactivated motility of bull sperm is triggered at the axoneme by $\mathrm{Ca}^{2+}$ and not cAMP. Developmental Biology 250 208-217. (doi:10.1006/dbio.2002.0797)

Hoogewijs $M$, Rijsselaere $T$, De Vliegher $S$, Vanhaesebrouck E, De Schauwer C, Govaere J, Thys M, Hoflack G, Van Soom A \& de Kruif A 2010 Influence of different centrifugation protocols on equine semen preservation. Theriogenology 74 118-126. (doi:10.1016/j.theriogenology.2010.01.022)

Hunter RH 1987 Human fertilization in vivo, with special reference to progression, storage and release of competent spermatozoa. Human Reproduction 2 329-332.

Hunter RH 1991 Oviduct function in pigs, with particular reference to the pathological condition of polyspermy. Molecular Reproduction and Development 29 385-391. (doi:10.1002/mrd.1080290411)

Hunter RH 1993 Sperm:egg ratios and putative molecular signals to modulate gamete interactions in polytocous mammals. Molecular Reproduction and Development 35 324-327. (doi:10.1002/mrd.1080350315)

Hunter RH 1995 Human sperm reservoirs and Fallopian tube function: a role for the intra-mural portion? Acta Obstetricia et Gynecologica Scandinavica 74 677-681. (doi:10.3109/00016349509021173)

Hunter RH 1996 Ovarian control of very low sperm/egg ratios at the commencement of mammalian fertilisation to avoid polyspermy. Molecular Reproduction and Development 44 417-422. (doi:10.1002/ (SICI)1098-2795(199607)44:3 < 417::AID-MRD15>3.0.CO;2-X)

Hunter RH 2005a Fallopian tube physiology: preliminaries to monospermic fertilization and cellular events post-fertilization. Ernst Schering Research Foundation Workshop 52 245-261.

Hunter RH 2005b The Fallopian tubes in domestic mammals: how vital is their physiological activity? Reproduction, Nutrition, Development 45 281-290. (doi:10.1051/rnd:2005020)

Hunter RH 2008 Sperm release from oviduct epithelial binding is controlled hormonally by peri-ovulatory graafian follicles. Molecular Reproduction and Development 75 167-174. (doi:10.1002/mrd.20776)

Hunter RH 2012 Components of oviduct physiology in eutherian mammals. Biological Reviews of the Cambridge Philosophical Society 87 244-255. (doi:10.1111/j.1469-185X.2011.00196.x)

Hunter RH, Petersen HH \& Greve T 1999 Ovarian follicular fluid, progesterone and $\mathrm{Ca}^{2+}$ ion influences on sperm release from the fallopian tube reservoir. Molecular Reproduction and Development 54 283-291. (doi:10.1002/ (SICI)1098-2795(199911)54:3 <283::AID-MRD9> 3.0.CO;2-T)

Kirichok Y \& Lishko PV 2011 Rediscovering sperm ion channels with the patch-clamp technique. Molecular Human Reproduction 17 478-499. (doi:10.1093/molehr/gar044)

Kirichok Y, Navarro B \& Clapham DE 2006 Whole-cell patch-clamp measurements of spermatozoa reveal an alkaline-activated $\mathrm{Ca}^{2+}$ channel. Nature 439 737-740. (doi:10.1038/nature04417)

Leemans B, Gadella BM, Sostaric E, Nelis H, Stout TA, Hoogewijs M \& Van Soom A 2014 Oviduct binding and elevated environmental ph induce protein tyrosine phosphorylation in stallion spermatozoa. Biology of Reproduction 91 13. (doi:10.1095/biolreprod.113.116418)
Lefebvre R \& Suarez SS 1996 Effect of capacitation on bull sperm binding to homologous oviductal epithelium. Biology of Reproduction 54 575-582. (doi:10.1095/biolreprod54.3.575)

Li HG, Ding XF, Liao AH, Kong XB \& Xiong CL 2007 Expression of CatSper family transcripts in the mouse testis during post-natal development and human ejaculated spermatozoa: relationship to sperm motility. Molecular Human Reproduction 13 299-306. (doi:10.1093/molehr/gam009)

Lishko PV \& Kirichok Y 2010 The role of Hv1 and CatSper channels in sperm activation. Journal of Physiology 588 4667-4672. (doi:10.1113/ jphysiol.2010.194142)

Lishko PV, Botchkina IL \& Kirichok Y 2011 Progesterone activates the principal $\mathrm{Ca}^{2+}$ channel of human sperm. Nature 471 387-391. (doi:10. 1038/nature09767)

Loomis PR \& Graham JK 2008 Commercial semen freezing: individual male variation in cryosurvival and the response of stallion sperm to customized freezing protocols. Animal Reproduction Science 105 119-128. (doi:10.1016/j.anireprosci.2007.11.010)

Loux SC, Crawford KR, Ing NH, Gonzalez-Fernandez L, Macias-Garcia B, Love CC, Varner DD, Velez IC, Choi YH \& Hinrichs K 2013 CatSper and the relationship of hyperactivated motility to intracellular calcium and $\mathrm{pH}$ kinetics in equine sperm. Biology of Reproduction 89 123. (doi:10. 1095/biolreprod.113.111708)

Marquez B \& Suarez SS 2007 Bovine sperm hyperactivation is promoted by alkaline-stimulated $\mathrm{Ca}^{2+}$ influx. Biology of Reproduction 76 660-665. (doi:10.1095/biolreprod.106.055038)

Marquez B, Ignotz G \& Suarez SS 2007 Contributions of extracellular and intracellular $\mathrm{Ca}^{2+}$ to regulation of sperm motility: release of intracellular stores can hyperactivate CatSper1 and CatSper2 null sperm. Developmental Biology 303 214-221. (doi:10.1016/j.ydbio.2006.11.007)

McPartlin LA, Littell J, Mark E, Nelson JL, Travis AJ \& Bedford-Guaus SJ 2008 A defined medium supports changes consistent with capacitation in stallion sperm, as evidenced by increases in protein tyrosine phosphorylation and high rates of acrosomal exocytosis. Theriogenology 69 639-650. (doi:10.1016/j.theriogenology.2007.11.016)

McPartlin LA, Suarez SS, Czaya CA, Hinrichs K \& Bedford-Guaus SJ 2009 Hyperactivation of stallion sperm Is required for successful in vitro fertilization of equine oocytes. Biology of Reproduction 81 199-206. (doi:10.1095/biolreprod.108.074880)

Neill JM \& Olds-Clarke P 1987 A computer-assisted assay for mouse sperm hyperactivation demonstrates that bicarbonate but not bovine serum albumin is required. Gamete Research 18 121-140. (doi:10.1002/mrd. 1120180204)

Nelis H, D'Herde K, Goossens K, Vandenberghe L, Leemans B, Forier K, Smits K, Braeckmans K, Peelman L \& Van Soom A 2014 Equine oviduct explant culture: a basic model to decipher embryo-maternal communication. Reproduction, Fertility, and Development 26 954-966. (doi:10. 1071/RD13089)

Nikpoor P, Mowla SJ, Movahedin M, Ziaee SA \& Tiraihi T 2004 CatSper gene expression in postnatal development of mouse testis and in subfertile men with deficient sperm motility. Human reproduction 19 124-128. (doi:10.1093/humrep/deh043)

Olson SD, Fauci LJ \& Suarez SS 2011 Mathematical modeling of calcium signaling during sperm hyperactivation. Molecular Human Reproduction 17 500-510. (doi:10.1093/molehr/gar040)

Ortgies F, Klewitz J, Gorgens A, Martinsson G \& Sieme H 2012 Effect of procaine, pentoxifylline and trolox on capacitation and hyperactivation of stallion spermatozoa. Andrologia 44 (Suppl 1) 130-138. (doi:10.1111/ j.1439-0272.2010.01150.x)

Overstreet JW \& Cooper GW 1979 Effect of ovulation and sperm motility on the migration of rabbit spermatozoa to the site of fertilization. Journal of Reproduction and Fertility 55 53-59. (doi:10.1530/jrf.0. 0550053)

Parrish JJ, Susko-Parrish J, Winer MA \& First NL 1988 Capacitation of bovine sperm by heparin. Biology of Reproduction 38 1171-1180. (doi:10.1095/biolreprod38.5.1171)

Pinyopummintr T \& Bavister BD 1994 Development of bovine embryos in a cell-free culture medium: effects of type of serum, timing of its inclusion and heat inactivation. Theriogenology 41 1241-1249. (doi:10.1016/ 0093-691X(94)90481-W)

Publicover S, Harper CV \& Barratt C $2007\left[\mathrm{Ca}^{2+}\right] \mathrm{i}$ signalling in sperm making the most of what you've got. Nature Cell Biology 9 235-242. (doi:10.1038/ncb0307-235) 
Quill TA, Ren D, Clapham DE \& Garbers DL 2001 A voltage-gated ion channel expressed specifically in spermatozoa. PNAS 98 12527-12531. (doi:10.1073/pnas.221454998)

Quill TA, Sugden SA, Rossi KL, Doolittle LK, Hammer RE \& Garbers DL 2003 Hyperactivated sperm motility driven by CatSper2 is required for fertilization. PNAS 100 14869-14874. (doi:10.1073/pnas.2136654100)

Quirk SM \& Fortune JE 1986 Plasma concentrations of gonadotrophins, preovulatory follicular development and luteal function associated with bovine follicular fluid-induced delay of oestrus in heifers. Journal of Reproduction and Fertility 76 609-621. (doi:10.1530/jrf.0. 0760609)

Rath D, Long CR, Dobrinsky JR, Welch GR, Schreier LL \& Johnson LA 1999 In vitro production of sexed embryos for gender preselection: high-speed sorting of X-chromosome-bearing sperm to produce pigs after embryo transfer. Journal of Animal Science 77 3346-3352.

Rathi R, Colenbrander B, Bevers MM \& Gadella BM 2001 Evaluation of in vitro capacitation of stallion spermatozoa. Biology of Reproduction $\mathbf{6 5}$ 462-470. (doi:10.1095/biolreprod65.2.462)

Ren D, Navarro B, Perez G, Jackson AC, Hsu S, Shi Q, Tilly JL \& Clapham DE 2001 A sperm ion channel required for sperm motility and male fertility. Nature 413 603-609. (doi:10.1038/35098027)

Rodriguez H, Torres C, Valdes X, Guerra H, Pastor LM, Maccallini G \& Bustos-Obregon E 2001 The acrosomic reaction in stallion spermatozoa: inductive effect of the mare preovulatory follicular fluid. Biocell $\mathbf{2 5}$ $115-120$.

Strunker T, Goodwin N, Brenker C, Kashikar ND, Weyand I, Seifert R \& Kaupp UB 2011 The CatSper channel mediates progesterone-induced $\mathrm{Ca}^{2+}$ influx in human sperm. Nature 471 382-386. (doi:10.1038/ nature09769)

Suarez SS 1998 The oviductal sperm reservoir in mammals: mechanisms of formation. Biology of Reproduction 58 1105-1107. (doi:10.1095/ biolreprod58.5.1105)

Suarez SS 2001 Carbohydrate-mediated formation of the oviductal sperm reservoir in mammals. Cells, Tissues, Organs 168 105-112. (doi:10. 1159/000016811)

Suarez SS 2008a Regulation of sperm storage and movement in the mammalian oviduct. International Journal of Developmental Biology $\mathbf{5 2}$ 455-462. (doi:10.1387/ijdb.072527ss)

Suarez SS $2008 b$ Control of hyperactivation in sperm. Human Reproduction Update 14 647-657. (doi:10.1093/humupd/dmn029)

Suarez SS \& Osman RA 1987 Initiation of hyperactivated flagellar bending in mouse sperm within the female reproductive tract. Biology of Reproduction 36 1191-1198. (doi:10.1095/biolreprod36.5.1191)
Suarez SS \& Pacey AA 2006 Sperm transport in the female reproductive tract. Human Reproduction Update 12 23-37. (doi:10.1093/humupd/ dmi047)

Talevi R \& Gualtieri R 2001 Sulfated glycoconjugates are powerful modulators of bovine sperm adhesion and release from the oviductal epithelium in vitro. Biology of Reproduction 64 491-498. (doi:10.1095/ biolreprod64.2.491)

Therien I, Bergeron A, Bousquet D \& Manjunath P 2005 Isolation and characterization of glycosaminoglycans from bovine follicular fluid and their effect on sperm capacitation. Molecular Reproduction and Development 71 97-106. (doi:10.1002/mrd.20287)

Tremoleda JL, Stout TAE, Lagutina I, Lazzari G, Bevers MM, Colenbrander B \& Galli C 2003 Effects of in vitro production on horse embryo morphology, cytoskeletal characteristics, and blastocyst capsule formation. Biology of Reproduction 69 1895-1906. (doi:10.1095/ biolreprod.103.018515)

Triglia RP \& Linscott WD 1980 Titers of nine complement components, conglutinin and C3b-inactivator in adult and fetal bovine sera. Molecular Immunology 17 741-748. (doi:10.1016/0161-5890(80)90144-3)

Xia J \& Ren D 2009 The BSA-induced $\mathrm{Ca}^{2+}$ influx during sperm capacitation is CATSPER channel-dependent. Reproductive Biology and Endocrinology 7 119. (doi:10.1186/1477-7827-7-119)

Yanagimachi R 1969 In vitro capacitation of hamster spermatozoa by follicular fluid. Journal of Reproduction and Fertility 18 275-286. (doi:10.1530/jrf.0.0180275)

Yanagimachi R 1994 Mammalian fertilization. In The Physiology of Reproduction, pp 189-317. Eds E Knobil \& J Neill. New York, NY: Raven Press.

Yao Y, Ho P \& Yeung WS 2000 Effects of human follicular fluid on the capacitation and motility of human spermatozoa. Fertility and Sterility $\mathbf{7 3}$ 680-686. (doi:10.1016/S0015-0282(99)00637-8)

Yoo SW, Bolbot T, Koulova A, Sneeringer R, Humm K, Dagon Y \& Usheva A 2013 Complement factors are secreted in human follicular fluid by granulosa cells and are possible oocyte maturation factors. Journal of Obstetrics and Gynaecology Research 39 522-527. (doi:10.1111/j. 1447-0756.2012.01985.x)

Received 16 April 2015

First decision 13 May 2015

Revised manuscript received 8 June 2015

Accepted 18 June 2015 